\title{
Life as a fortress - structure, function, and adaptive values of morphological and chemical defense in the oribatid mite Euphthiracarus reticulatus (Actinotrichida)
}

Michael Heethoff ${ }^{1,2^{* \dagger}} \mathbb{D}$, Adrian Brückner ${ }^{1,2,8+}$, Sebastian Schmelzle ${ }^{1+}$, Mario Schubert ${ }^{3+}$, Maria Bräuer ${ }^{4}$, Reinhard Meusinger ${ }^{5}$, Stefan Dötterl ${ }^{6}$, Roy A. Norton ${ }^{7}$ and Günther Raspotnig ${ }^{2}$

\begin{abstract}
Background: Oribatid mites are among the primordial decomposer faunal elements and potential prey organisms in soil. Among their myriad morphological defenses are strong sclerotization and mineralization, cuticular tecta, and the "ptychoid" body-form, which allows to attain an encapsulated, seed-like appearance. Most oribatid mites possess a pair of exocrine glands that produce blends of hydrocarbons, terpenes, aromatics, alkaloids and cyanogenic compounds. Many species evolved "holistic" defensive strategies by combining several morphological and chemical traits.

Methods: We describe the morphological and chemical bases of defense in the ptychoid oribatid Euphthiracarus reticulatus. The functional morphology was investigated with synchrotron X-ray microtomography (SRHCT) and highspeed life-radiography. Gland secretions were collected from 20,000 adult specimens, purified and fractionated by preparative capillary gas chromatography (pcGC) and analyzed by gas chromatography / mass spectrometry (GC/MS), high-resolution mass spectrometry (HRMS), and nuclear magnetic resonance spectroscopy (NMR). The adaptive values of morphological and chemical defenses were estimated in bioassays against three predators: a similar-sized gamasid mite (Stratiolaelaps miles, ca. $0.8 \mathrm{~mm}$, with slender chelicera for piercing membranous cuticular regions), and two larger staphylinid beetles, Stenus juno (ca. $7 \mathrm{~mm}$, bearing a harpoon-like sticky labium and sickle-shaped mandibles) and Othius punctulatus (ca. $14 \mathrm{~mm}$, bearing plesiomorphic chewing mandibles).
\end{abstract}

Results: The secretions comprised two components: the diterpene $\beta$-springene and a novel compound with a mass of $276 \mathrm{~g} / \mathrm{mol}$ - eventually elucidated as 2-(but-1-en-1-yl)-4-butylidene-3-(pent-2-en-1-yl)-pentanedial, to which we assign the trivial name $\delta$-acaridial. Upon attacks by S. juno, E. reticulatus reacted quickly: within $150 \mathrm{~ms}$ from the first contact the encapsulation was almost completed - less time than the beetle needed to retract the labium and transfer the mite to the mandibles. Chemically-defended specimens of E. reticulatus effectively repelled all predators. After depletion of oil-gland reservoirs, however, O. punctulatus easily fed on the mites while S. miles and S. juno were not able to overcome the morphological barrier of strong cuticle and ptychoid body form.

Conclusion: Such an effective, holistic defense strategy, involving both morphological and chemical traits, probably carries high resource-costs, but it allows adult euphthiracaroid mites to occupy an almost "enemy-free space" despite the high diversity of predators in soil.

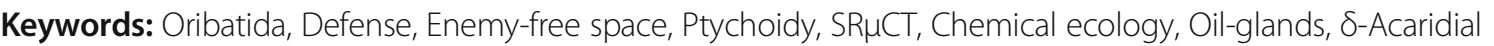

\footnotetext{
* Correspondence: heethoff@bio.tu-darmstadt.de

${ }^{\dagger}$ Michael Heethoff, Adrian Brückner, Sebastian Schmelzle and Mario Schubert contributed equally to this work.

${ }^{1}$ Ecological Networks, Technische Universität Darmstadt, Schnittspahnstraße

3, 64287 Darmstadt, Germany

Institute of Biology, University of Graz, Universitätsplatz 2, 8010 Graz, Austria

Full list of author information is available at the end of the article
}

(c) The Author(s). 2018 Open Access This article is distributed under the terms of the Creative Commons Attribution 4.0 International License (http://creativecommons.org/licenses/by/4.0/), which permits unrestricted use, distribution, and reproduction in any medium, provided you give appropriate credit to the original author(s) and the source, provide a link to the Creative Commons license, and indicate if changes were made. The Creative Commons Public Domain Dedication waiver (http://creativecommons.org/publicdomain/zero/1.0/) applies to the data made available in this article, unless otherwise stated. 


\section{Background}

Soil ecosystems comprise the most speciose animal communities on earth and their enigmatically high diversity and complex trophic interactions have been recognized for several decades [1-4]. While the general macrostructure of belowground food-webs has been studied to some extent $[5,6]$, the microstructure of such networks and its distinct feeding interactions remain mostly unknown $[4$, 7]. At this level, a more mechanistic, trait-based understanding of predator-prey interactions in soil seems mandatory, since many soil organisms possess different types of feeding mechanisms on the one hand and defense mechanisms on the other [8-11].

Oribatid mites represent a particularly good model to study adaptive values of defensive traits in soil food-webs because they evolved a matchless spectrum of potential anti-predation adaptions $[8,9,12-14]$. Oribatid mites are mostly small $(<1 \mathrm{~mm})$, particle-feeding detritivores and fungivores found in nearly every soil ecosystem of the world, as well as in miscellaneous non-soil microhabitats [15-18]. Combined with high densities (up to several hundred thousand individuals per square meter) this renders them a valuable potential food source for soil predators $[13,19]$. Generally, defensive traits in adult oribatid mites fall into two major classes. Morphological traits include: strong sclerotization or biomineralization of the cuticle [20-22]; protection of vulnerable soft parts by localized coverings or modifications of the whole body-form, such as ptychoidy ([14, 23]; Fig. 1, Additional file 1: Video S1); and/or jumping capabilities [24, 25]. Chemical traits mostly relate to a pair of large opisthonotal exocrine glands (= oil-glands) which produce a remarkable diversity of repellent and/or toxic substances, such as hydrocarbons, aromatics, terpenes, alkaloids, and cyanogenic compounds [26-31]. Juveniles of most oribatid mites lack strong sclerotization and rely on chemical defense [32] or predator avoidance by an endophagous life style [13, 33].

Ptychoidy is a specialized body-form in which the animal can encapsulate by retracting its legs and mouthparts into a secondary cavity that is then covered by the deflected prodorsum ([14, 23, 34]; Figs. 1, 2). This ability to encapsulate probably evolved three times independently: twice in the infraorder Enarthronota (independently in Protoplophoridae and Mesoplophoridae), and once in the Mixonomata (Ptyctima, comprising Euphthiracaroidea and Phthiracaroidea), and all of these groups combine it with cuticular hardening through biomineralization [35]. However, only within Ptyctima, the so-called 'box mites', and here only in Euphthiracaroidea, is ptychoidy combined with chemical defense [36]. Their diverse defensive adaptations led to the conclusion that oribatid mites live in a conceptual "enemy-free space" [9, 10, 12, 19, 32], where only a small fraction of predators can feed on them $[8,9,31,37-41]$. However, maintaining this "enemy-free space" is costly $[12,42]$ and no single strategy can provide protection against all types of predators $[8,9,32]$.

We investigated the defensive biology of the oribatid mite species Euphthiracarus reticulatus Berlese, adults of which possess multiple potentially defensive traits (biomineralization, ptychoidy, oil-glands) comprising an ideal model system for delineating adaptive values of different anti-predator strategies. Generalist predators-one predatory mite and two staphylinid beetles-were used as model predators, rather than the highly specialized scydmaenid beetles, which already have been investigated to some extent [37-40].

Herein, we address the mechanical basis of defense by describing the functional morphology of ptychoidy based on tomographic data and high-speed life radiography. We also analyzed the defensive gland secretions and elucidated the structure of a novel natural product by combing several analytical techniques (pcGC, GC/MS, HRMS, NMR). Bioassays of morphological and chemical defense revealed a "holistic" combination of protective traits with a twofold function: hardened cuticle and the ptychoid defensive mechanism protect the mites against predators of the same size and even larger ones that lack strong mandibles; chemical defense is effective against all, but most important against large predators with the mechanical potential (large mandibles) to crack the mineralized cuticle.

\section{Methods}

\section{Animals used in this study}

Adult individuals of the oribatid mite Euphthiracarus reticulatus Berlese (Euphthiracaroidea: Euphthiracaridae) were field-sampled from leaf litter and organic fermentation layer of mixed-forest soils near Ferlach and Maria Rain

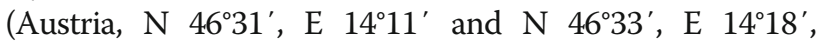
respectively). This is the first record for this species in Austria. Mites were collected using Berlese-Tullgren funnels. Mites for predation experiments and high-speed videography were collected in summer 2011, kept on moss and mixed litter from the collection site. Specimens for morphological analysis (SR $\mu \mathrm{CT}, \mathrm{X}$-ray radiography) were collected in November 2014 and had a notogaster length between 870 and $940 \mu \mathrm{m}$. For chemical analyses, about 20,000 adult specimens were collected between August and November 2014, and between May and November 2015.

We further used Phthiracarus sp. Perty (Phthiracaroidea: Phthiracaridae) as prey for comparative feeding experiments. In contrast to euphthiracaroid mites, the Phthiracaroidea evolved a ptychoid body form without lateral elasticity [14] and they lack chemical defense, due to the loss of oil-glands [36].

Specimens of the staphylinid beetle Stenus juno Paykull $(N=15)$ were collected from the reed zone of a small pond near Tübingen (Germany; N 48 $31^{\prime}$, E $\left.9^{\circ} 00^{\prime}\right)$; those of Othius punctulatus Goeze $(N=2)$ were collected near the botanical garden in Darmstadt (Germany; N 49 $52^{\prime}$, 


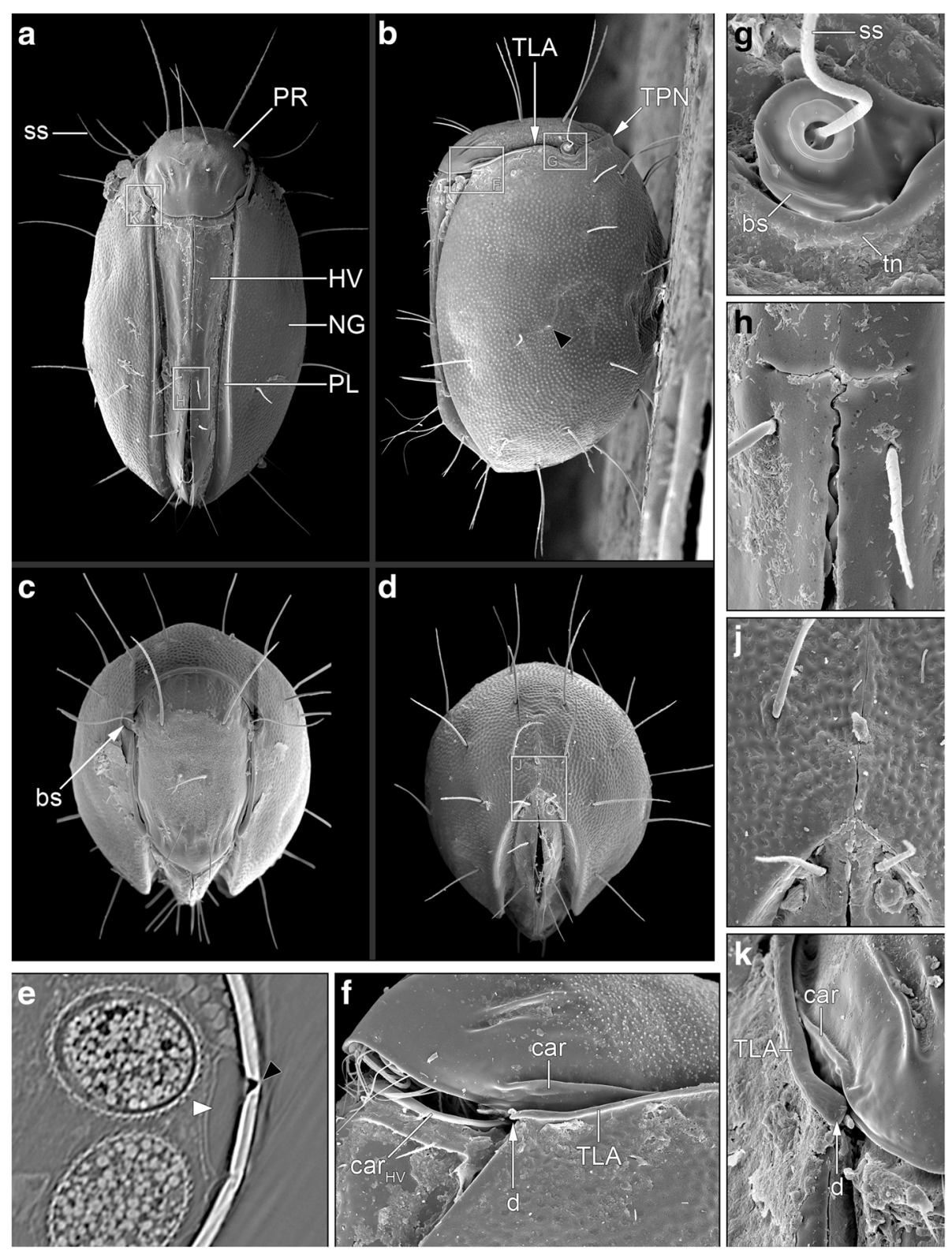

Fig. 1 Scanning electron micrographs (a-d, f-k) and SRHCT data (e) of several adult specimens of Euphthiracarus reticulatus. a Ventral view. b Lateral view. Black arrowhead points to gland opening (see also e) c Anterior view. d Posterior view. e Pore of the opisthonotal gland (black arrowhead) and reservoir (white arrowhead). $\mathbf{f}$ Detail of the prodorsum and lateral anterior tectum, lateral view. $\mathbf{g}$ Detail of the bothridial scale; note the stress marks. $\mathbf{h}$ Detail of the anterior interlocking triangle. $\mathbf{j}$ Detail of posterior view showing the notogastral fissure. The faint posterior interlocking triangle is not visible. $\mathbf{k}$ Detail of the prodorsum and lateral anterior tectum, anterior view. bs, bothridial scale; car, carina of the prodorsum; $\mathrm{Car}_{\mathrm{HV}}$, carina of the holoventral plates; d, ventral tooth of lateral anterior tectum; HV, holoventral plates; NG, notogaster; PL, plicature plates; PR, prodorsum; ss, sensillus; TLA, lateral anterior tectum; tn, tectonotal notch; TPN, pronotal tectum

E $\left.008^{\circ} 41^{\prime}\right)$. Individuals of both species were kept in plastic boxes on a moist mixture of plaster of Paris and charcoal (9:1) and fed with springtails. The common soil-dwelling gamasid mite Stratiolaelaps miles Berlese (Laelapidae) was purchased from a commercial supplier (Schneckenprofi, Prime Factory $\mathrm{GmbH}$ \& Co. KG, Hennstedt, Germany). All predators were starved for five days prior to the feeding experiments.

\section{Sample preparation}

Specimens for morphological analysis were fixed either in $70 \%(\mathrm{~V} / \mathrm{V})$ ethanol $(\mathrm{EtOH})$ or FAE, (3:6:1; $\mathrm{V} / \mathrm{V} / \mathrm{V}$ mixture of $35 \%$ formaldehyde, $80 \%$ ethanol, and $100 \%$ acetic acid), and transferred to $70 \% \mathrm{EtOH}$ after $72 \mathrm{~h}$. Samples for SR $\mu \mathrm{CT}$ were contrasted with $1 \%$ iodine solution (in $70 \% \mathrm{EtOH}$ ) for $24 \mathrm{~h}$ and washed in $80 \% \mathrm{EtOH}$ for 30 min before scanning. 


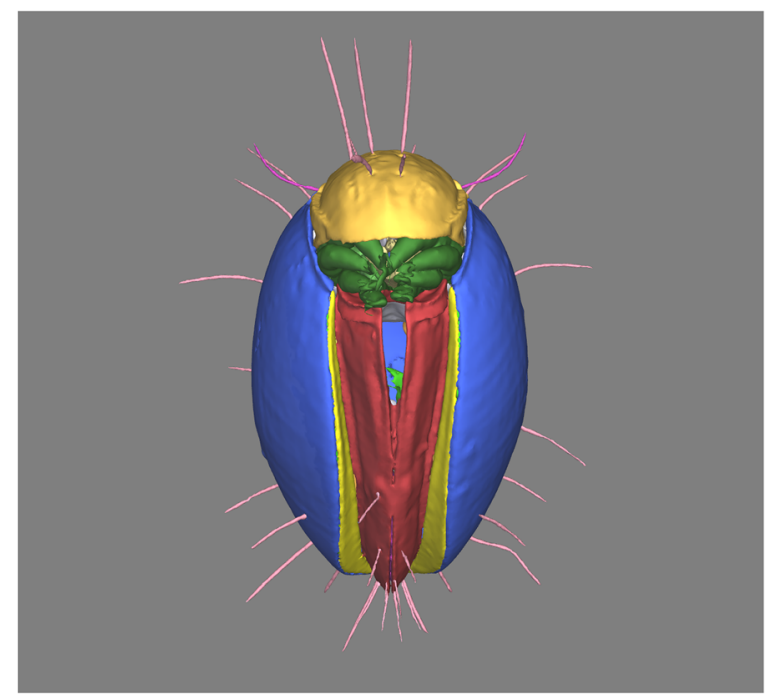

Fig. 2 3D model containing all exoskeletal and muscular features associated with ptychoidy in Euphthiracarus reticulatus. Please see Additional file 14 containing the interactive 3D content. Within this file, various presets for different views are available. The gladius of the preanal apodeme is part of the apodematal complex of the holoventral plates, but for better visualization modeled as a separate material. Muscle color corresponds to one of the four muscle systems: shades of red, dorsoventral muscles of the prosoma (DVP); shades of turquoise, endosternal division of the prosoma (EDP); shades of purple, longitudinal division of the prosoma (LDP); shades of green, opisthosomal compressor system (OCS); shades of orange, muscles not associated with any of the four above mentioned systems

\section{Scanning electron microscopy}

Specimens were critical-point dried (Polaron E3000, UK), and either fixed to stubs with silver paint onto a T-section-like metal foil or directly onto a stub and then sputter-coated with a $20 \mathrm{~nm}$ thick layer of gold-palladium (Balzers SCD 030, Germany). Micrographs were taken on a Zeiss Evo LS10 scanning electron microscope at $15 \mathrm{kV}$.

\section{Synchrotron X-ray microtomography and radiography $(\mathrm{SR} \mu \mathrm{CT})$}

The SR $\mu$ CT was performed at the TOPO-TOMO beamline (ANKA, Karlsruhe Institute of Technology, Germany). The sample was scanned with a beam energy of $20 \mathrm{keV}$ and 3000 projections within a $180^{\circ}$ rotation $(300$ projections per second). A scintillator converted X-rays into visible light which was then recorded by a cooled CCD sensor with a resolution of $2016 \times 2016$ pixels. We used a magnification of $10 \times$ with a resulting effective pixel size of $1.22 \mu \mathrm{m}$. Live radiography was performed with 300 radiographs per second, and the same energy and effective pixel size on three living specimens from a ventral, anterior, and lateral view. Although $\mathrm{SR} \mu \mathrm{CT}$ is considered to be a non-destructive imaging method, the ionizing radiation
[43] may lead to a release of gas visible inside the mite, which might be accompanied by the destruction of membranes, and tissues such as muscles and nerves [43].

\section{Visualization of SR $\mu \mathrm{CT}$ data}

Segmentation and three-dimensional modeling were conducted with Amira 5.6.0 (FEI, Munich, Germany; Fig. 2). We further prepared a model from a single material, comprising all internal structures to measure the volume of the animal (Additional file 2: Figure S1). Throughout, we apply the established methodology and terminology [14, 34]. Unless stated otherwise, the mentioned muscles are paired, and the number of muscle fibers refers to one side only.

\section{Videography}

High-speed recordings were performed with a Photron Fastcam SA3 (Photron Ltd., West Wycombe, UK) with 500 frames per second. Additional recordings with 25 frames per second were made with a Panasonic Lumix DMC-GH2 (Panasonic Deutschland, Hamburg, Germany) mounted on a Zeiss Stemi 2000-C (Carl Zeiss AG, Oberkochen, Germany). Recordings were analyzed in FIJI [44, 45].

\section{Functional analyses}

We cut the radiographies only to show ptychosis, split each into two time periods (a fast first phase and a slower second one), combined them into one video and aligned them so that onset, 'break' (cf. Fig. 3), and end of enptychosis (encapsulation) are at the same point in time, and finally cropped the video to 200 frames (resulting in a stretched first phase, and a compressed second phase). We then placed 32 Landmarks in total (see Additional file 3: Table S1, and Additional file 4: Figure S2 a-c) on every second frame of the videos using FIJI 2.0.0 [44], which resulted in 101 time points and thus 3232 single data points.

We used the $\mathrm{X}$ and $\mathrm{Y}$ coordinates of these data points to calculate 26 distances (see Additional file 3: Table S2, Additional file 4: Figure S2 d-f) using Pythagoras theorem

$$
\mathrm{d}_{(X, Y)}=\sqrt{\left(X_{2}^{2}-X_{1}^{2}\right)+\left(Y_{2}^{2}-Y_{1}^{2}\right)}
$$

and calculated the angle $\alpha$ (between notogaster and prodorsum; in degrees) using the distances $\mathrm{A}, \mathrm{A}_{\mathrm{b}}$, and $\mathrm{A}_{\mathrm{c}}$ (see Additional file 3: Table S2, Additional file 4: Figure S2a) with

$$
\alpha=\frac{180}{\pi} \cdot \cos ^{-1}\left(\frac{A_{b}^{2}+A_{c}^{2}-A^{2}}{2 A_{b} A_{c}}\right) .
$$

We did the same for the angles between the ventral plates with the respective sides (angles between plicature and holoventral plates and between the holoventral plates; cf. Fig. 4). 

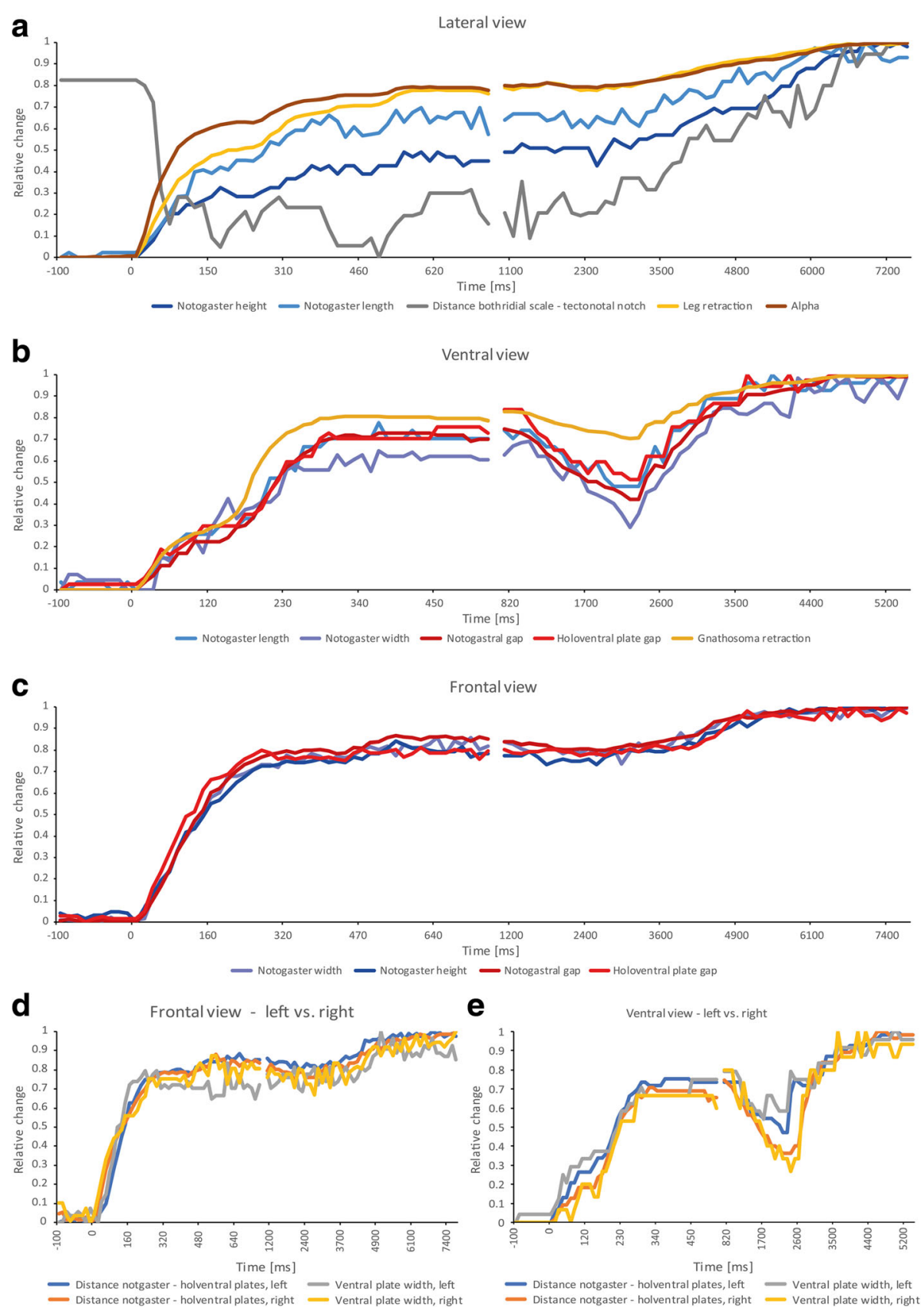

Fig. 3 Normalized change over time (rounded) for given distances and angles during a period of $7.2 \mathrm{~s}(\mathbf{a}), 5.2 \mathrm{~s}(\mathbf{b}, \mathbf{e})$, and $7.4 \mathrm{~s}(\mathbf{c}, \mathbf{d}) \mathrm{starting}$ at the first sign of encapsulation. a Distances and angle alpha calculated based on landmarks placed on the radiography from a lateral view. $\mathbf{b}$ Distances calculated based on landmarks placed on the radiography from a ventral view. c Distances calculated based on landmarks placed on the radiography from a frontal view. $\mathbf{d}$ Comparison of distances of the left and right side of the animal calculated based on landmarks placed on the radiography from a frontal view. e Comparison of distances of the left and right side of the animal calculated based on landmarks placed on the radiography from a ventral view

For better visualization and comparison, we calculated the delta of all distances, i.e., the change in distance over time, and normalized the values (scale from 0 to 1 , where 0 represents the extended state and 1 the encapsulated state).

Based on radiographs of extended and encapsulated state in frontal view of the radiography data, we labeled the cross-sectional area (cf. insets in Fig. 4b, c) in Amira, and measured the resulting area in FIJI [44, 45]. Based on these we prepared approximate 2D models, adjusted in size to the real states using the angles between the ventral plates (see above; Fig. 4b, c), and measured the resulting areas in FIJI. Taking the circumference of the notogaster 


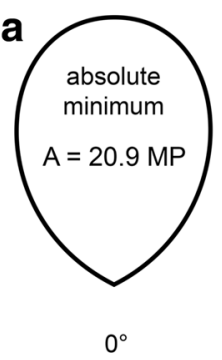

e
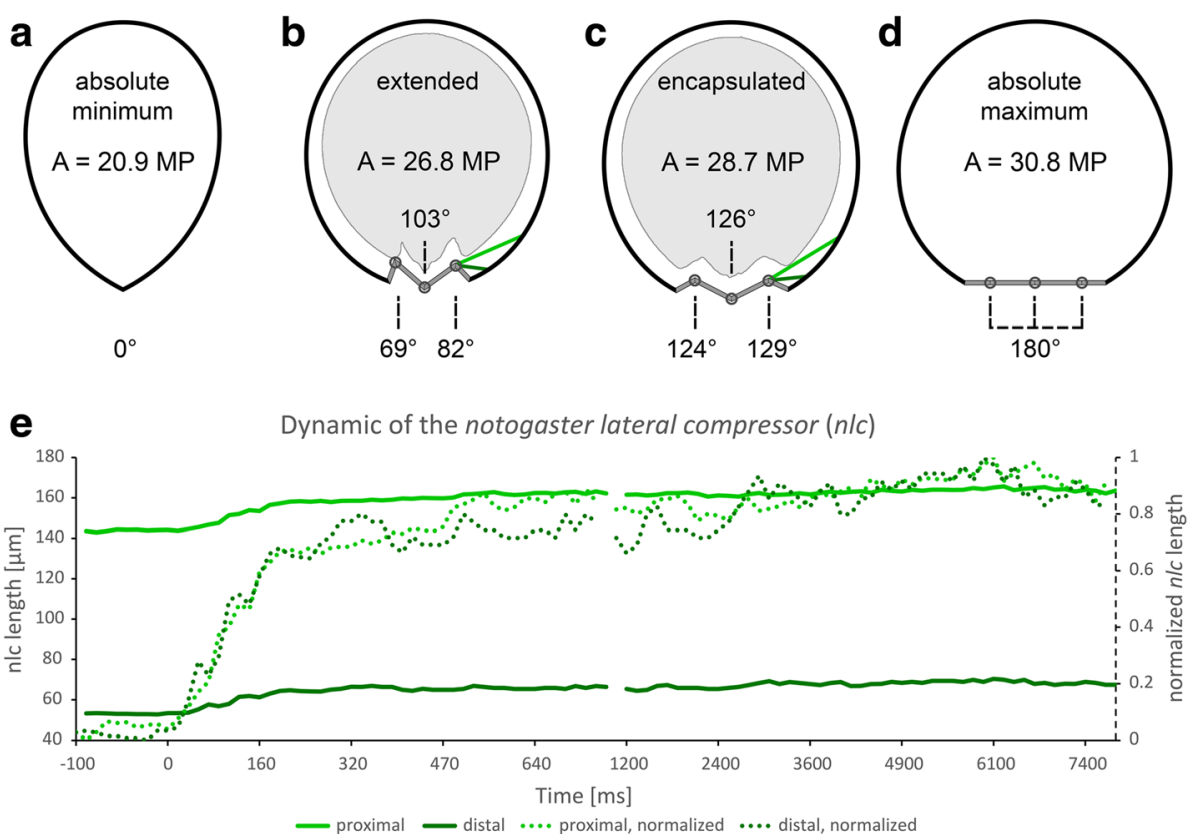

— proximal — distal .... proximal, normalized .... distal, normalized

Fig. 4 Schematic drawings of Euphthiracarus reticulatus showing medial cross sections of modeled natural (with real areas at $85 \%$ size in the background; $\mathbf{b}, \mathbf{c}$ ) and theoretical states (a, d). Note the angles (above and below) between the different plates. Circles indicate position of joints between different ventral plates. e Dynamics of the notogaster lateral compressor (nlc) in the course of enptychosis (time is rounded). The solid lines refer to the primary axis and show the length of the nlc, whereas the dotted lines refer to the secondary axis and show the normalized change in length (where 0 represents the extended state and 1 the encapsulated state)

and the width of the ventral plates (holoventral and plicature plates) into account, we additionally prepared models for a theoretical minimum and a maximum state (Fig. 4a, d). In the theoretical minimum state, the notogastral gap is entirely closed, i.e., the lateral edges of the notogaster come into contact and the angle between the different ventral plates is $0^{\circ}$. In the theoretical maximum state, the notogastral gap is as wide as possible, i.e., the angle between the respective ventral plates is $180^{\circ}$ and the distance of the edges of the notogastral gap is the sum of the width of all ventral plates.

We calculated the dynamic of a proximal and a distal portion of the notogaster lateral compressor muscle (nlc) based on the radiography data (frontal view; Fig. 4e). The minimum and maximum length of the nlc, however, do not reflect the full dynamic of the muscle. A normal physiological contraction reduces a vertebrate muscle to about $65 \%$ and it can be stretched to $115 \%$ [46]. The maximum contraction is about $50 \%$ of the resting length [47]. The same applies to the insect muscle [48]. Assuming the maximum calculated length of the $n l c$ is the resting length, we calculated the dynamic for 50,65 and $115 \%$ of the resting length.

\section{Preparation of oil gland secretion extracts}

Oil-gland secretions of E. reticulatus were extracted by submersion of freshly collected, living individuals in hexane (purity $\geq 99 \%$, Merck, Darmstadt, Germany) for $10 \mathrm{~min}$. Pooled extracts (up to 200 individuals per extract) were prepared by using $50 \mu$ l hexane per 25 specimens and stored at $-20^{\circ} \mathrm{C}$ for further processing.

\section{Gas chromatography - Mass spectrometry (GC-MS)}

Crude extracts of E. reticulatus were analyzed with a QP 2010ultra GC/MS (Shimadzu, Kyōto, Japan). The gas chromatograph (GC) was equipped with a ZB-5MS fused silica capillary column $(30 \mathrm{~m} \times 0.25 \mathrm{~mm} \mathrm{ID}, \mathrm{df}=0.25 \mu \mathrm{m})$ from Phenomenex (Torrance, USA). Sample aliquots of $1.5 \mu \mathrm{l}$ were injected by using an AOC-20i autosampler-system from Shimadzu, into a PTV-split/splitless-injector (Optic 4, ATAS GL, Eindhoven, Netherlands), which operated in splitless-mode. Injection-temperature was programmed from an initial $50{ }^{\circ} \mathrm{C}$ up to $230{ }^{\circ} \mathrm{C}$ (heating-rate of $5{ }^{\circ} \mathrm{C} / \mathrm{sec}$ ) and then an isothermal hold until the end of the $\mathrm{GC}$ run. Hydrogen was used as carrier-gas with a constant flow rate of $3.05 \mathrm{ml} / \mathrm{min}$. The temperature of the GC oven was raised from an initial $50{ }^{\circ} \mathrm{C}$ for $1 \mathrm{~min}$, to $300{ }^{\circ} \mathrm{C}$ with a heating-rate of $10{ }^{\circ} \mathrm{C} / \mathrm{min}$ and then an isothermal hold at $300{ }^{\circ} \mathrm{C}$ for $5 \mathrm{~min}$. Electron ionization mass spectra were recorded at $70 \mathrm{eV}$ with a scan rate of $2 \mathrm{scans} / \mathrm{sec}$ from $\mathrm{m} / \mathrm{z}$ 40 to 550 . Ion source and transfer line were kept at 200 and $310^{\circ} \mathrm{C}$, respectively. Gas chromatographic retention indices (RI) of extracted compounds were calculated using an alkane standard mixture $\left(C_{9}-C_{33}\right.$ dissolved in hexane) [49]. The quantitative amounts of oil-gland exudates of E. reticulatus ( $N=45$ specimen) were calculated based on the 
sesquiterpene $\beta$-farnesene ((6E)-7,11-dimethyl-3-methylene-1,6,10-dodecatriene; $\rho_{\mathrm{i}}=15 \mathrm{ng} / \mu \mathrm{l}$ ) as internal standard.

Derivatization of potential hydroxyl groups to corresponding trimethyl-silyl (=TMCS)-ethers was conducted with N-methyl-N-(trimethylsilyl)-trifluoracetamid (MSTFA in pyridine $2: 1$; with $1 \%$ trimethylchlorosilane), while potential carbonyl groups were derivatized using MOX (2\% methoxyamine-hydrogen chloride in pyridine; for details see Additional file 3).

The oil-gland secretion of the euphthiracaroid species Oribotritia berlesei Michael [36] was used as a natural source for $\beta$-springene for comparison of chromatographic retention indices (RI) and fragmentation patterns. The alkane standard, $\beta$-farnesene and all derivatization chemicals were acquired from Sigma-Aldrich (St. Louis, USA).

\section{Liquid chromatography - High-resolution mass spectrometry (LC-HRMS)}

High resolution mass spectrometry (HRMS) was carried out on a Q-exactive high-resolution orbitrap MS with a heated electrospray source coupled to an Accela 1250 HPLC pump (Thermo Fisher Scientific, St. Louis, USA). For the analysis, hexane solvent was gently removed under nitrogen gas-flow and the residual compounds were subsequently resolved in $100 \mu \mathrm{l}$ methanol $(\geq 99.9 \%$, Roth, Karlsruhe, Germany). Samples were analyzed by direct infusion ESI-MS and by HPLC-MS equipped with a reversed phase Hypersil Gold column $(100 \times 2.1 \mathrm{~mm}$ ID, $\mathrm{df}=1.9 \mu \mathrm{m}$; Thermo Fisher Scientific, St. Louis, USA). The unknown compound was observed as $[\mathrm{M}+\mathrm{H}]^{+}$- ions as well as Na- and K-adducts.

\section{Preparative capillary gas chromatography (pcGC)}

Purification and fraction-collection of the main compound was accomplished by preparative gas chromatography using a preparative fraction collector (PFC). The GC-PFC system consisted of a gas chromatograph equipped with a flame ionization detector (Agilent 7890A, Santa Clara, USA) and a PFC device (Gerstel, Mühlheim an der Ruhr, Germany). A ZB-5 fused silica capillary column (30 m $\times$ $0.32 \mathrm{~mm}$ ID, $0.25 \mu \mathrm{m}$ ) from Phenomenex (Torrance, USA) was used for the analyses and hydrogen was used as carrier gas with a flow rate of $3 \mathrm{ml} / \mathrm{min}$. The column was split at the end by a $\mu$ Flow splitter (Gerstel, Mühlheim an der Ruhr, Germany) into two deactivated capillary columns leading to the FID ( $2 \mathrm{~m} \times 0.15 \mathrm{~mm}$ ID) and PFC ( $1 \mathrm{~m} \times$ $0.2 \mathrm{~mm}$ ID). Nitrogen makeup gas with a flow rate of $25 \mathrm{ml} / \mathrm{min}$ was applied to the splitter. The PFC was connected with the GC oven via a heated transfer line which was connected to seven transfer capillaries with an eight port zero-dead volume valve via the deactivated column (for further information about the setup see [50, 51]). $3.5 \mu \mathrm{l}$ sample aliquots were injected to a MMI injector (Agilent, Santa Clara, USA) which was heated from $50{ }^{\circ} \mathrm{C}$ (holding time $0.25 \mathrm{~min}$ ) up to $250{ }^{\circ} \mathrm{C}$ (heating-rate of $12{ }^{\circ} \mathrm{C} / \mathrm{sec}$ ). The temperature of the $\mathrm{GC}$ oven was raised from $40{ }^{\circ} \mathrm{C}$ to $250{ }^{\circ} \mathrm{C}$ with a heating rate of $25{ }^{\circ} \mathrm{C}$ per minute. Sampling time was $1 \mathrm{~min}$ and the transfer line of the PFC was heated to $230{ }^{\circ} \mathrm{C}$. Glass tubes filled with $50 \mathrm{mg}$ Carbotrap B (mesh 20-40, Supelco, Bellefonte, USA) and deactivated glass wool were used as volatile traps. Collected fractions were frozen to $-20{ }^{\circ} \mathrm{C}$. The main compound was collected from $8.6 \mathrm{~min}$ to $8.7 \mathrm{~min}$ and stored for NMR analysis at $-20^{\circ} \mathrm{C}$.

\section{Nuclear magnetic resonance spectroscopy (NMR)}

NMR spectra were measured either on a Bruker Avance III $700 \mathrm{MHz}$ spectrometer equipped with a TCI cryoprobe or a Bruker Avance III HD $600 \mathrm{MHz}$ spectrometer with a QXI room temperature probe (both Bruker Biospin, Karlsruhe, Germany) at $274 \mathrm{~K}$ using $\mathrm{CD}_{2} \mathrm{Cl}_{2}(99.96 \% \mathrm{D}$ from Sigma) as solvent. The concentration of the sample was $\sim 20 \mathrm{nmol} / \mathrm{l}$ as estimated from the integral intensity of the residual solvent signal, corresponding to $\sim 3 \mu \mathrm{g}$. The temperature was calibrated with methanol- $\mathrm{d}_{4}$. An external sample of $\mathrm{CD}_{2} \mathrm{Cl}_{2}$ containing $0.03 \%$ TMS was used for referencing. Chemical shift assignment was achieved with $2 \mathrm{D}{ }^{1} \mathrm{H}^{-1} \mathrm{H}$ TOCSY (total correlated spectroscopy, mixing times of $80 \mathrm{~ms}$ ), $2 \mathrm{D}^{1} \mathrm{H}-{ }^{1} \mathrm{H}$ COSY (correlated spectroscopy), 2D ${ }^{1} \mathrm{H}_{-}{ }^{13} \mathrm{C}$ HSQC (heteronuclear single quantum correlation), 2D ${ }^{1} \mathrm{H}_{-}{ }^{13} \mathrm{C}$ HMBC (heteronuclear multiple-bond correlation) and ${ }^{1} \mathrm{H} 1 \mathrm{D}$ spectra, using the Bruker pulse sequences mlevphpp, cosygpmfphpp, hsqcedetgpsisp2.2, hmbcgplpndprqf, and zg30, respectively. 1D ${ }^{1} \mathrm{H}$ spectra were recorded using an excitation pulse of $30^{\circ}$ and a repetition time of $4.5 \mathrm{~s}, 128$ scans were added and Fourier transformed with a final digital resolution of $0.09 \mathrm{~Hz}$. The hetero-nuclear long-range correlation spectrum (HMBC) was recorded by a matrix of $4 \mathrm{k}$ data points (f2, ${ }^{1} \mathrm{H}$ dimension) and 256 increments (data points in $\mathrm{f} 1{ }^{13} \mathrm{C}$ dimension). The spectral width was $10 \times$ $206 \mathrm{ppm}$, corresponding to a digital resolution $1.6 \mathrm{ppm}$ in $\mathrm{f} 1,3.6 \mathrm{~Hz}$ in $\mathrm{f} 2.256$ scans for every increment were added resulting in an experimental time of $36 \mathrm{~h}$. The spectrum has been optimized for a heteronuclear coupling constant of $9 \mathrm{~Hz}$. More experimental details are found in the figure captions. Raw data were processed with Topspin 3.2 (Bruker Biospin, Karlsruhe, Germany) and 2D data were analyzed using Sparky 3.115 [52].

\section{Predation experiments}

Specimens of E. reticulatus $(N=60)$ were chemically disarmed by dipping them three times into hexane for $1 \mathrm{~min}$, with an hour of intermediate recovery between the steps. This procedure leads to complete depletion of defensive oil-glands [53]. Circular plastic cuvettes $(2.1 \mathrm{~cm} \mathrm{ID} \times 2.2 \mathrm{~cm})$ were used as arenas. The floor was covered with a moist piece of filter paper. For the experiments with Stenus juno (7 mm body size), 30 attacks 
were observed using disarmed mites (with empty oil-glands) and 30 with freshly sampled (i.e. chemically defended) control mites. The experimental procedure included: (i) randomly choosing a $S$. juno specimen (from $N=15$ ), placing it in the arena and waiting for approx. $5 \mathrm{~min}$, (ii) placing a mite (control or disarmed) inside the arena, (iii) waiting for a labial attack of the beetle, (iv) documenting the success and handling time of the attack, (v) discarding the mite and arena, replacing the beetle among the others to randomize experienced/ unexperienced specimens. Handling times (manipulation of mite by the beetle) were used as indicators of chemical defense and categorized as: $0-1 \mathrm{~s}, 1-5 \mathrm{~s}$ and $>5 \mathrm{~s}$. The first category $(0-1 \mathrm{~s})$ means that the mite was released immediately after it came into contact with the mandibles - an indication of repellent secretions [9, 32]. The second category (1-5 s) indicates that the beetle turned the mite in its mouthparts for some seconds, usually until the mouthparts came into contact with the glandular regions of the mite. The third category ( $>5 \mathrm{~s}$ ) indicates that the beetle tried to crack and feed on the mite over a longer time period without being repelled. Significant differences of handling times between control and disarmed mites were tested with a $2 \times 3 x^{2}$-test as global test and affiliated pairwise one-dimensional $X^{2}$-tests after false-discovery rate correction [54].

To test the adaptive values of morphological and chemical defense of $E$. reticulatus against a common small predator (the gamasid mite $S$. miles, $0.8 \mathrm{~mm}$ body size), and a large staphylinid beetle $(O$. punctulatus, $14 \mathrm{~mm}$ body size) we performed feeding experiments on an observational basis without a statistical design and observed prey handling with chemically defended/undefended $E$. reticulatus for several hours. Also, on an observational basis, we tested feeding success of all predators on Phthiracarus sp., which lack lateral elasticity and chemical defense.

\section{Results \\ Morphology \\ Morphological characteristics}

The morphology of $E$. reticulatus follows the basic ptychoid body plan of the Euphthiracaroidea that has been described in detail for Euphthiracarus cooki Norton, Sanders \& Minor [23]. Most morphological differences are minor and have little influence on the ptychoid defensive mechanism; these are described and discussed in the Additional file 3 . The following summarizes the more important traits needed to understand functioning.

The holoventral plates of adult E. reticulatus have a weakly pronounced anterior interlocking triangle (Fig. $1 \mathrm{~h}$ ), and an even weaker posterior interlocking triangle (based on the SR $\mu \mathrm{CT}$ data). Preanal and postanal apodemes are connected by firm cuticle, the sclerotized walls of the anal atrium (aa; Figs. 2, 5). The preanal apodeme is anteriorly extended into a gladius-like appendix, hence termed gladius of the preanal apodeme $\left(g l_{p r a}\right.$; Figs. 2, 5; Additional file 5: Figure S3), which is anteriorly limited by, but not in contact with, the genital atrium. These four parts (preanal and postanal apodemes, the sclerotized walls of the anal atrium, and the anteriorly-extending gladius of the preanal apodeme) make up the apodematal complex of the holoventral plates.

The notogaster lateral compressor $(n l c)$ consists of 18 muscle bands with 2-3 muscle fibers each and inserts directly on the medial margin of the plicature plate (Fig. 5). The ventral plate adductor (vpa, about 12-16 muscle fibers) and part of the ventral plate compressor ( $v p c$, about 16-18 muscle fibers) insert on the gladius of the preanal apodeme, with another part of the $v p c$ inserting directly on the preanal apodeme (Fig. 5). A postanal muscle is absent. The lateral rectal muscle (3 muscle fibers; $(\mathrm{rm}$ ) originates dorsally on the notogaster and inserts dorsolaterally on the rectum.

\section{Functional morphology}

Three specimens of Euphthiracarus reticulatus have been recorded during enptychosis from a lateral, ventral, and frontal view using high-speed Synchrotron X-ray radiography (Fig. 6). On average it took $6.7 \mathrm{~s}$ for full encapsulation (Fig. 3). Enptychosis is characterized by a fast onset (Fig. 3), i.e., the initial deflection of the prodorsum (Fig. 3a), a long plateau phase, in which the animals may extend again (Fig. 3b), and a slow final encapsulation. The speed of change in notogaster width and height is slower in comparison to the deflection of the prodorsum and the retraction of the legs (Fig. 3a). Overall, the progression of all calculated distances and angles is highly synchronized (for example Fig. 3c), except for the distance of the bothridial scale and tectonotal notch (Fig. 3a; cf. Figs. 1b, g, 5c, Additional file 6: Figure S7a). There is no visible difference between the left and right side of the animal (Fig. 3d, e).

During enptychosis, the angle enclosed by the holoventral plates (cf. Figs. 3c, 4, 5) changed from $103^{\circ}$ to $126^{\circ}$, and the mean angle (averaged left and right) enclosed by the plicature and holoventral plates from $76^{\circ}$ to $127^{\circ}$. The notogastral gap width increased from $181 \mu \mathrm{m}$ to $277 \mu \mathrm{m}$.

The length of the distal muscle portion of the $n l c$ changed from 52.7 to $70.4 \mu \mathrm{m}$ during enptychosis (Table 1; Fig. 4b, c, e), and the length of the proximal muscle portion of the $n l c$ from 142.9 to $165.7 \mu \mathrm{m}$, which corresponds to an average change of $20 \%$ with reference to the maximum length. An assumed maximal contraction of the $n l c$ to $50 \%$ of the resting length (cf. Material and Methods, section Functional analysis) would lead to a calculated length of $35.2 \mu \mathrm{m}$ for the distal muscle portion and $82.9 \mu \mathrm{m}$ for the proximal muscle portion, and an assumed normal contraction to $65 \%$ of the resting 


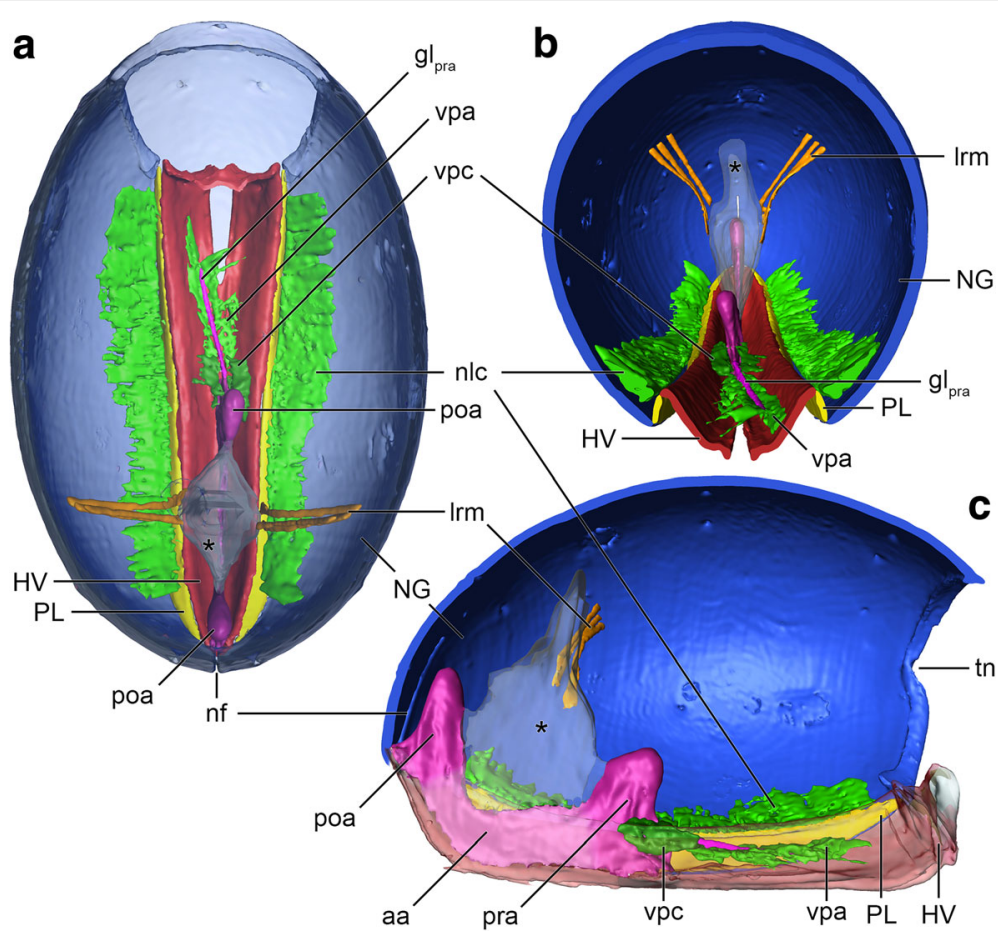

Fig. 5 3D-models of reconstructed Synchrotron X-ray micro tomography data of muscles of the opisthosomal compressor system (in green) and associated exoskeletal elements. a Dorsal view on the opisthosomal compressor system with transparent notogaster. $\mathbf{b}$ Virtual cross section of idiosoma, frontal view. c) Virtual sagittal section of idiosoma, lateral view with transparent holoventral plates. Note the brighter region of the apodematal complex of the holoventral plates. aa, sclerotized wall of the anal atrium; gl pra, gladius of the preanal apodeme; HV, holoventral plates; Irm, lateral rectal muscle; nf, notogastral fissure; NG, notogaster; nlc, notogaster lateral compressor; PL, plicature plates; poa, postanal apodeme; pra, preanal apodeme; tn, tectonotal notch; vpa, ventral plate adductor; vpc, ventral plate compressor. Asterisk indicates the transparently displayed rectum

length to a length of $45.7 \mu \mathrm{m}$ (distal) and $107.7 \mu \mathrm{m}$ (proximal). Stretching of the $n l c$ to $115 \%$ of the resting length would lead to $80.9 \mu \mathrm{m}$ and $190.6 \mu \mathrm{m}$ for the distal and proximal muscle portions, respectively.

The measurements for extended and encapsulated states based on the radiography data resulted in a cross-sectional area of 0.277 and $0.304 \mathrm{~mm}^{2}$, respectively (insets in Fig. 4b, c; Table 2). The 2D models of extended and encapsulated state yielded an area of 0.277 and $0.297 \mathrm{~mm}^{2}$, respectively (Fig. 4b, c; Table 2). Consequently, the deviation to the area measurements of the labeled cross-sectional radiography data is less than $1.2 \%$. The areas of simulated minimum and maximum states are 0.216 and $0.318 \mathrm{~mm}^{2}$, respectively (Fig. 4a, d; Table 2). The single material 3D model (Additional file 2: Figure S1; cf. Fig. 2) has a volume of $0.1646 \mathrm{~mm}^{3}$. The eggs of the morphological 3D model (six 'mature' and two 'immature') have a total volume of $0.0205 \mathrm{~mm}^{3}$ (12.48\% of the body volume).

\section{Chemistry}

Gas chromatography / mass spectrometry (GC/MS) analyses of oil gland secretions of $E$. reticulatus showed two peaks (Fig. 7a): $\beta$-springene (identified based on its $m / z$-fragmentation pattern, retention index and by comparison with a natural source [36]) as a minor compound (0.5-2\%) and an unknown major compound (98-99.5\%) with a molecular weight of $\mathrm{M}=276 \mathrm{~g} / \mathrm{mol}$ and base ions at $m / z=179$ and $m /$ $z=98$ (Fig. 7B, Additional file 3: Table S3). The mean amount of oil gland exudates extracted from individual $E$. reticulatus adults $(N=45)$ was $105 \pm 55 \mathrm{ng}$.

An initial comparison of the EI mass spectrum of the unknown compound with data from commercial libraries showed no accordance with any listed substance. High-resolution mass spectrometry (HRMS) gave an exact molecular weight of $\mathrm{M}=276.2086 \mathrm{~g} /$ mol (calculated $276.2089 \mathrm{~g} / \mathrm{mol}$ ), indicating an empirical molecular formula of $\mathrm{C}_{18} \mathrm{H}_{28} \mathrm{O}_{2}$. Derivatization with methoxyamine-hydrogen chloride (MOX) gave an adduct product with $m / z=334$ as molecular ion, indicating two carbonyl-groups in the molecule, while reactions with trimethylchlorosilane (TMCS) showed adducts with $m / z=348$ as molecular ion, indicating a hydroxyl group. When the compound was derivatized first with MOX, no TMCS adduct was found. When the compound was derivatized first with TMCS $(\mathrm{m} / \mathrm{z}$ $=348$ ) and with MOX afterwards, an adduct with $\mathrm{m} /$ $z=377$ as molecular ion was found. 

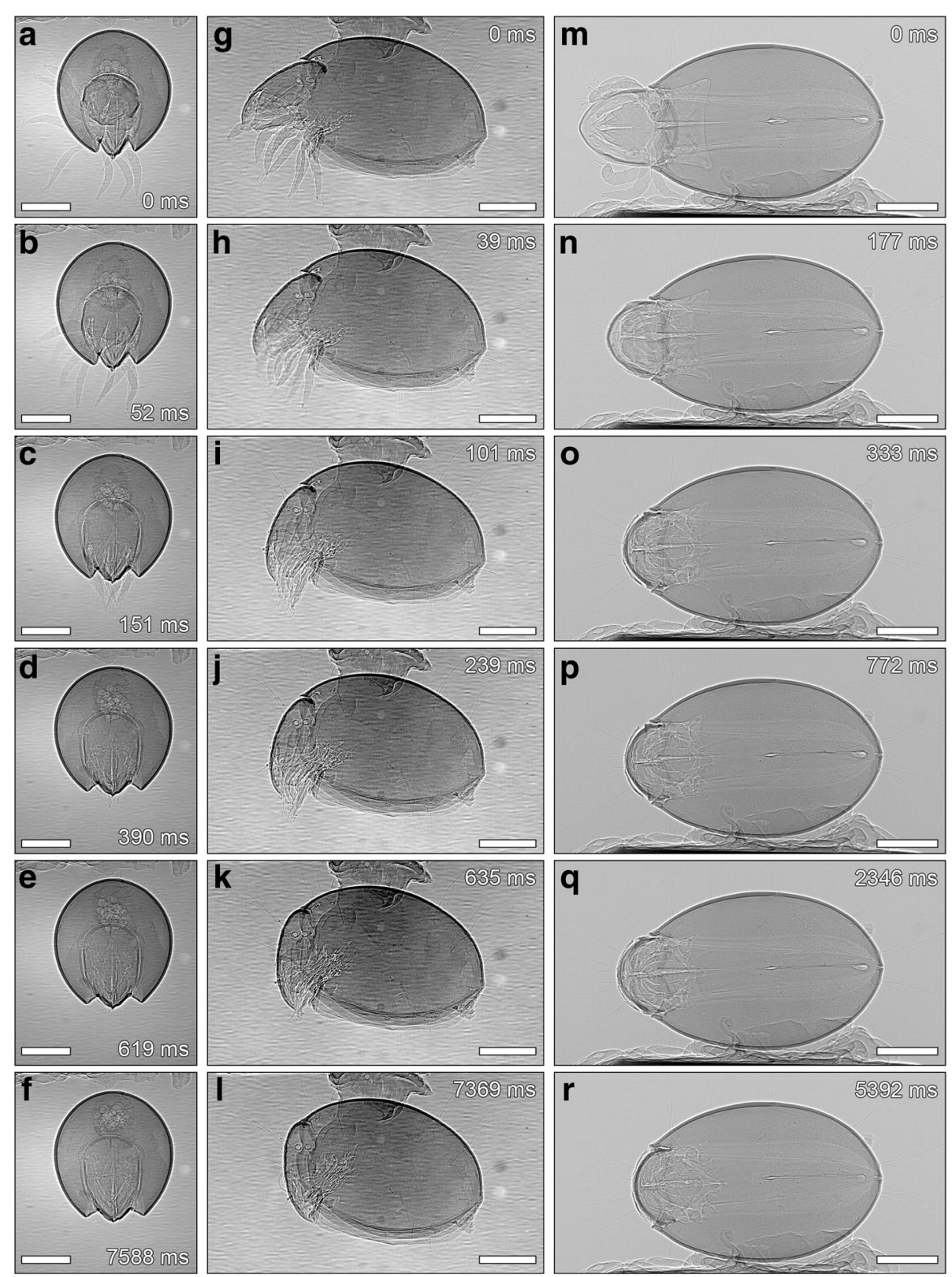

Fig. 6 Time series of cineradiography data showing enptychosis of adult Euphthiracarus reticulatus from different viewing angles. a-f frontal view; g-l lateral view; $\mathbf{m}-\mathbf{r}$ ventral view

The structural elucidation of the compound fractioned by pcGC with NMR spectroscopy $\left(1 \mathrm{D}^{1} \mathrm{H}, 2 \mathrm{D}{ }^{1} \mathrm{H}-{ }^{1} \mathrm{H}\right.$ TOCSY, 2D ${ }^{1} \mathrm{H}-{ }^{1} \mathrm{H}$ COSY, 2D ${ }^{1} \mathrm{H}_{-}{ }^{13} \mathrm{C}$ HSQC and, 2D ${ }^{1} \mathrm{H}^{13}{ }^{13} \mathrm{C}$ HMBC) revealed an acyclic, aliphatic pentyl-di-aldehyde subunit with three different alkenyl side chains (Fig. 8; Additional file 7: Figure S4). Thus, the IUPAC name of the compound is 2-(but-1-en-1-yl)-4-butylidene-3-(pent-2-en-1-yl)-pentanedial. Whereas the identification of the three alkenyl moieties and the two aldehyde groups was straightforward, connecting those individual parts was hampered by line broadening of the $\mathrm{H} 2$ and $\mathrm{H} 3$ signals of the pentyl-di-aldehyde subunit. This prevented the observation of correlations involving $\mathrm{C} 2$ and $\mathrm{C} 3$ in the $2 \mathrm{D}$ ${ }^{1} \mathrm{H}_{-}{ }^{13} \mathrm{C}$ HSQC spectrum (Additional file 7: Figure S4). However, many correlations of $\mathrm{H} 2$ and $\mathrm{H} 3$ are observed in the 2D ${ }^{1} \mathrm{H}_{-}{ }^{1} \mathrm{H}$ TOCSY (Fig. 8d) and a correlation between $\mathrm{H} 3$ and $\mathrm{H} 1 "$ in a $2 \mathrm{D}{ }^{1} \mathrm{H}-{ }^{1} \mathrm{H}$ COSY (Fig. 8c). Both aldehyde ${ }^{1} \mathrm{H}$ resonances showed correlations in $2 \mathrm{D}{ }^{1} \mathrm{H}-{ }^{1} \mathrm{H}$ TOCSY, including some with $\mathrm{H} 2$ and H3. The observed key correlations are summarized schematically in Fig. 8b. Chemical shifts of 
Table 1 Measured and calculated length dynamic of the notogaster lateral compressor ( $n / c$; cf. Fig. 4b, c, e, Additional file 4: Figure S2). All values are given in $\mu \mathrm{m}$ except if stated otherwise

\begin{tabular}{llll}
\hline & & Lateral n/c & Medial n/c \\
\hline Measured lengths & Minimum length & 52.7 & 142.9 \\
& Difference [\%] & 25.1 & 13.8 \\
& Maximum length & 70.4 & 165.7 \\
Calculated lengths $^{\mathrm{a}}{ }^{2}$ & Contraction about 50\% & 35.2 & 82.9 \\
& Contraction about 35\% & 45.7 & 107.7 \\
& Stretching to 115\% & 80.9 & 190.6 \\
\hline
\end{tabular}

abased on resting length of the muscle; cf. Materials and Methods, section Functional analyses

2-(but-1-en-1-yl)-4-butylidene-3-(pent-2-en-1-yl)-pentanedial measured in $\mathrm{CD}_{2} \mathrm{Cl}_{2}$ are listed in Additional file 3: Table S4. The stereochemistry of the two chiral carbons (C2 and C3) was not further determined. However, the fact that the stereo center $\mathrm{C} 2$ is located next to the aldehyde that can undergo keto-enol tautomerism implies that $\mathrm{C} 2$ is prone to racemization and thus the formation of diastereomers (Additional file 8: Figure S5). The proposed structure is further supported by the fragmentation pattern in the MS spectrum (Fig. 7c) which prominently displays all expected main fragments.

\section{Predation experiments}

Stenus juno individuals regularly attacked $E$. reticulatus, but both chemically defended $(=$ control $)$ and undefended (disarmed) mites were always well protected. However, handling times differed between defended and undefended specimens $\left(x^{2}=13.7, p=0.001, N=60\right.$; Fig. 9). While the shortest handling time was recorded more often for defended individuals $\left(0-1 \mathrm{~s} ; x^{2}=5.4, p=0.02\right)$, longer handling times were recorded predominantly for undefended individuals $\left(1-5 \mathrm{~s} ; \chi^{2}=6.3, p=0.01 \mid<5 \mathrm{~s} ; \mathrm{X}^{2}=\right.$ 2.0, $p=0.16)$. The response of $E$. reticulatus upon an attack by $S$. juno consisted of two phases: the reaction time of the mite (I) and the time needed for enptychosis (II). The time from attack to the first visible reaction of the mite (i.e. deflection of prodorsum) was around $50 \mathrm{~ms}$. This comprised the time of sensing the impact, processing the

Table 2 Areas of real and modeled cross-sectional states, and differences to the respective states (cf. 'Functional analysis' section in Material and Methods, and Fig. 4)

\begin{tabular}{lrllr}
\hline State & Minimum & Extended & Encapsulated & Maximum \\
\hline Measured $\left[\mu \mathrm{m}^{2}\right.$ ] & & 276,976 & 303,638 & \\
Difference [\%] & & 91.2 & 109.6 & \\
Modeled [ $\mathrm{mm}^{2}$ ] & 216,250 & 276,613 & 297,217 & 318,172 \\
Difference [\%] & 68 & 93.1 & 107.4 & 147.1 \\
\hline
\end{tabular}

neuronal input, and activating respective motor neurons. Enptychosis then took about $150 \mathrm{~ms}$, for a total time of about $200 \mathrm{~ms}$ (Fig. 10, Additional file 9: Video S2).

The gamasid mite Stratiolaelaps miles also readily attacked $E$. reticulatus, but never with success, irrespective of the chemical defense potential. In contrast, the large beetle Othius punctulatus was able to crack and feed on chemically undefended mites (Additional file 10: Video S3), while being repelled when oil gland secretions were present. None of the predators successfully attacked Phthiracarus sp., and even O. punctulatus was unable to crack the cuticle (Additional file 10: Video S3).

\section{Discussion}

\section{Morphology}

\section{Morphological characteristics}

The holoventral plate region of $E$. reticulatus exhibits some traits different from those of $E$. cooki and, at least in part, from all previously studied Euphthiracaroidea $[14,34,55]$. Among these are the apodematal complex of the holoventral plates including the gladius of the preanal apodeme that increases the insertion area mostly for the $v p a$, the weakly pronounced posterior interlocking triangle, and the absence of the postanal muscle (poam) (Figs. 1, 2, 5).

In $E$. cooki and other studied euphthiracaroid species $[34,55]$ the poam does not play a key role in ptychosis (in contrast to Phthiracaroidea; $[14,56,57])$; rather, it has a stabilizing function by counteracting the hemolymph pressure on the (holo-)ventral plates [14, 23] generated by the $n l c, v p a$, and $v p c$ (the number of muscle fibers for which is about the same as in E. cooki; Fig. 5). Stabilization could be accomplished partially by the lateral rectal muscles (lrm; orange muscle in Fig. 5; cf. [58]) in unison with a transmission of force created by the vpa via the apodematal complex.

In contrast to other euphthiracaroid mites, E. reticulatus has an apodematal complex of the holoventral plates consisting of the preanal and postanal apodemes, the sclerotized wall of the anal atrium, and the gladius of the preanal apodeme, where the vpa inserts exclusively, instead of on the preanal apodeme itself. A contraction of the vpa and resulting tension on the gladius could lead to a 'stiffening' of the sclerotized walls of the anal atrium and thus the whole apodematal complex. A contraction of the lrm then exerts force onto the reinforced apodematal complex and in turn onto the holoventral plates. The location of the lrm in the last third of the holoventral plates and the direction of its force vector perpendicular to the holoventral plates offers a nearly ideal situation for stabilizing the holoventral plates and thus might also allow for a weaker posterior interlocking triangle (the presence of which is ostensibly a trait of the genus). The parsimonious reduction of the plesiomorphic poam could indicate a 

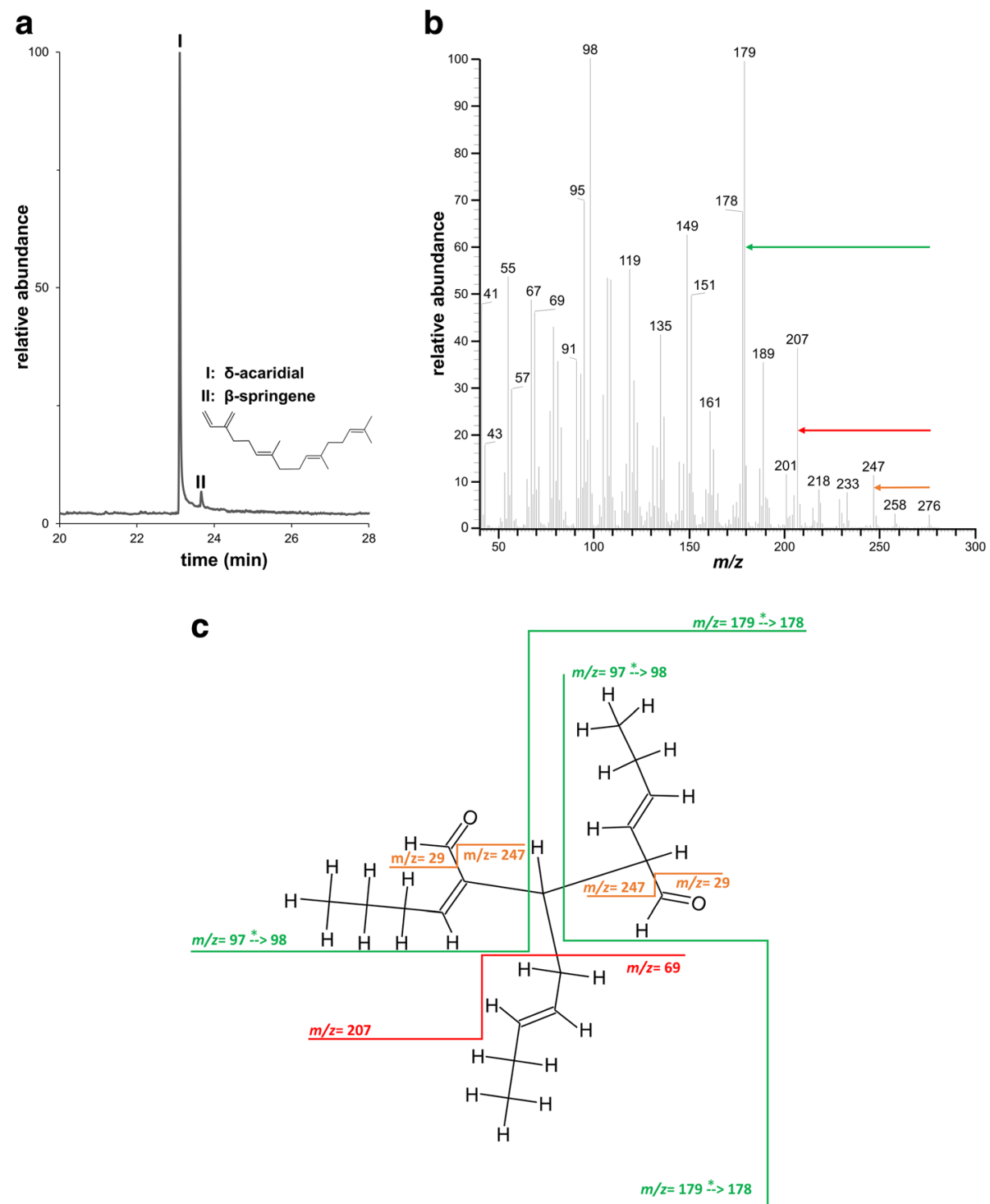

Fig. 7 Gas chromatogram (a) of the oil gland secretions of Euphthiracarus reticulatus. Peak I = $\delta$-acaridial, Peak $\|=\beta$-springene (see inserted molecular structure). Electron-ionization mass spectrum of $\delta$-acaridial (b). Interpretation of the main fragmentations (c), i.e. base ions and loss of function groups, of $\delta$-acaridial (* denotes a McLafferty rearrangement)

derived state of E. reticulatus with respect to E. cooki. In spite of the absence of the poam, the postanal apodeme of E. reticulatus is large. The combination of a large postanal apodeme and a sclerotized atrial wall could provide the elastic stability for keeping the vestibule closed. At the same time the modest sclerotization leaves the walls of the anal atrium flexible and does not obstruct defecation but might lead to a laterally flattened fecal pellet (see Additional file 11: Video S5).

\section{Functional morphology}

Complete encapsulation when attacked by Stenus juno is quick (200 ms), but the mites recorded with synchrotron high-speed radiography needed much longer $(6.7 \mathrm{~s}$ on average). The destructive factors of synchrotron radiation (see Material and Methods; Fig. 6a-f and Additional file 12: Video S4) might lead to a decreased morphological and neuronal performance, slowing down functional processes.

Nonetheless, the first phase of encapsulation is relatively quick (Fig. 3), followed by a plateau phase, during which the mites can 'decide' to either fully encapsulate (Fig. 3a, c) or reopen (Fig. 3b). Only when the disturbance remains does the mite finish enptychosis. This wait-and-see tactic might save energy, because the last phase of encapsulation seems to be strenuous [14]. All calculated angles and distances are highly synchronous over time, i.e. the sequence of enptychosis, except 

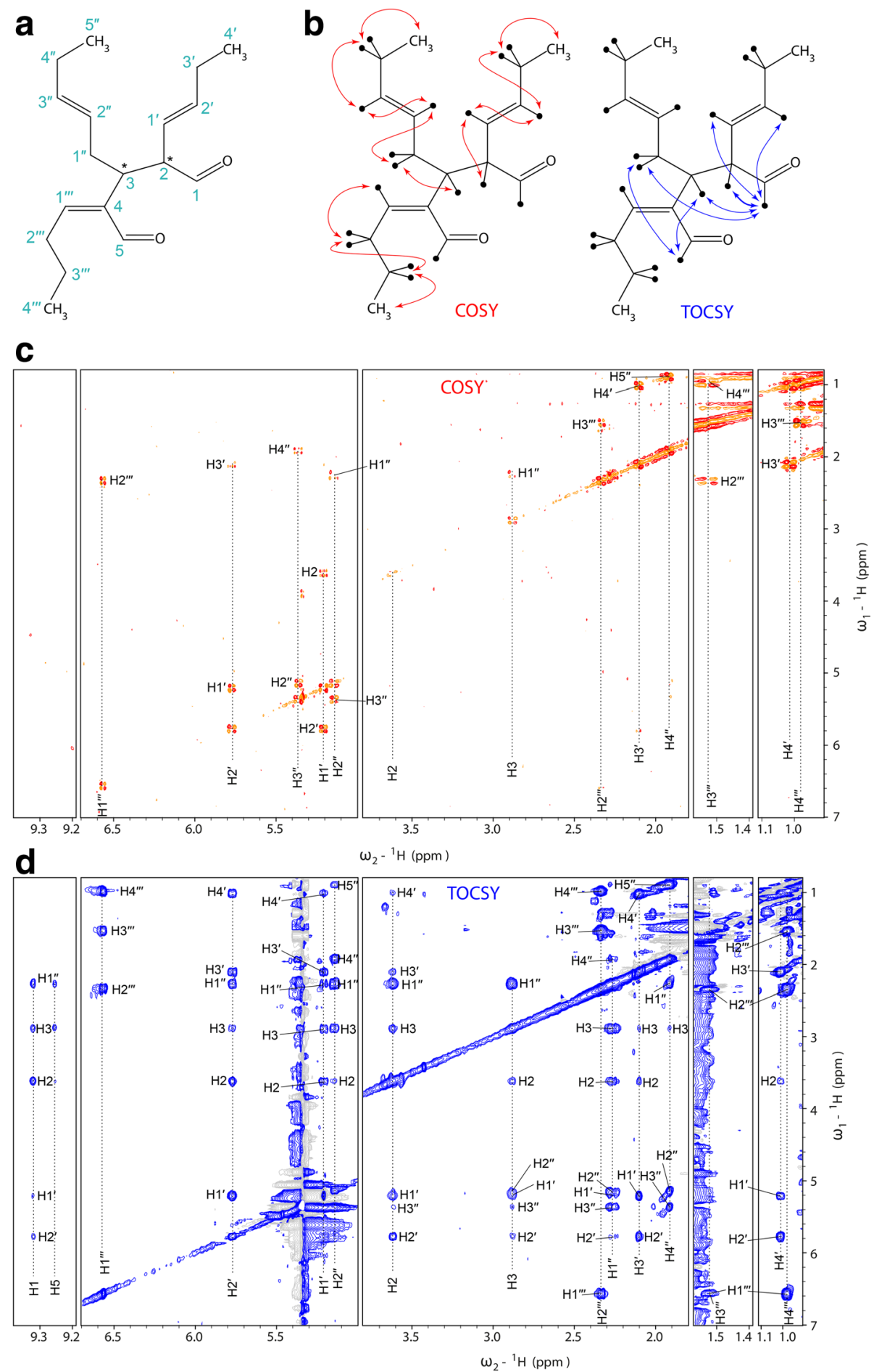

Fig. 8 Determination of the chemical structure of $\delta$-acaridial by NMR spectroscopy. a Chemical structure of $\delta$-acaridial showing the numbering of the individual carbon atoms, which is in accordance with its IUPAC name 2-(but-1-en-1-yl)-4-butylidene-3-(pent-2-en-1-yl)-pentanedial. Chiral centers are indicated with asterisks. $\mathbf{b}$ Schematic presentation of the key ${ }^{1} \mathrm{H}-{ }^{1} \mathrm{H}$ correlations observed in 2D COSY and TOCSY spectra. c Relevant regions of a 2D ${ }^{1} \mathrm{H}-{ }^{1} \mathrm{H}$ COSY spectrum recorded at $700 \mathrm{MHz}$ at $274 \mathrm{~K}$ using 16 transients, $2 \mathrm{k} \times 340$ data points, with spectral widths of $10 \times 10$ ppm, corresponding to a digital resolution of $7 \mathrm{~Hz}$ in $\mathrm{f} 2$ and $42 \mathrm{~Hz}$ in $\mathrm{f1}$, resulting in a measurement time of $3 \mathrm{~h}$. Positive signals are shown in red, negative ones in orange. d Corresponding regions of a $2 \mathrm{D}^{1} \mathrm{H}-{ }^{1} \mathrm{H}$ TOCSY spectrum recorded at $700 \mathrm{MHz}$ at $274 \mathrm{~K}$ using a mixing time of $80 \mathrm{~ms}, 16$ transients, $2 \mathrm{k} \times 256$ data points, with spectral widths of $10 \times 10 \mathrm{ppm}$, corresponding to a digital resolution of $7 \mathrm{~Hz}$ in $\mathrm{f} 2$ and $56 \mathrm{~Hz}$ in $\mathrm{f} 1$, resulting in a measurement time of 2.6 h. Negative signals are shown in grey 


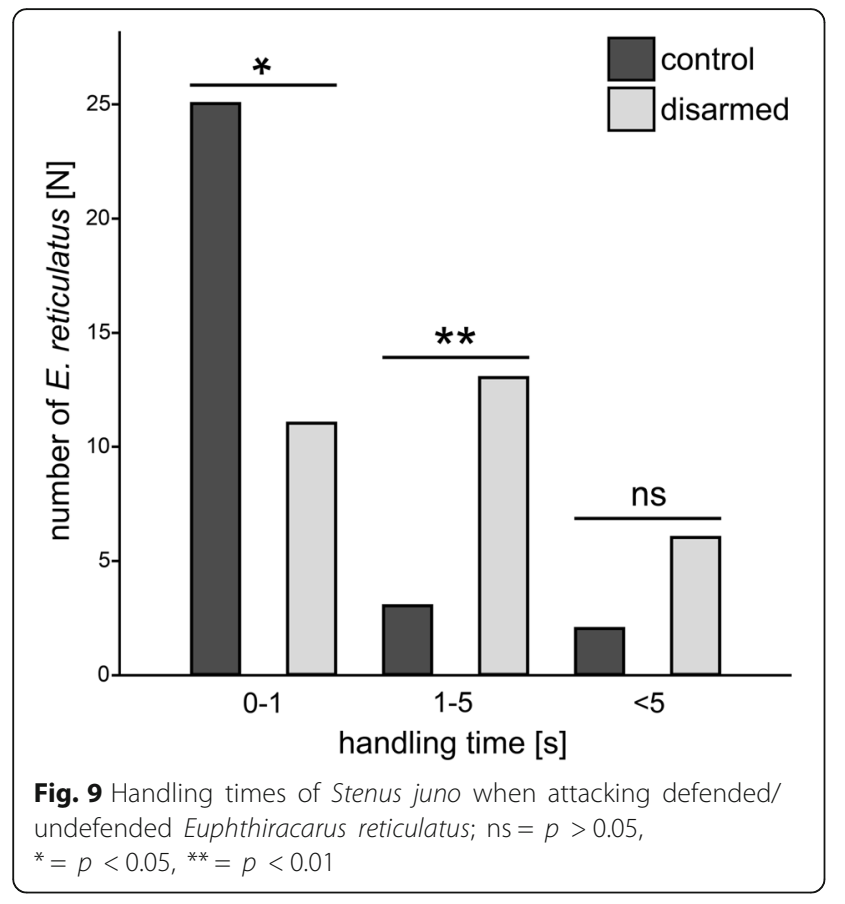

for the initially opposing movement of the bothridial scale (Fig. 3a). In the active, extended state the bothridial scale is in close contact with the tectonotal notch, acting as 'lazy hinge' during enptychosis [23], and in the encapsulated state it rests on top of the tectonotal notch. At the onset of enptychosis the bothridial scale has to be decoupled from the notogaster, thereby increasing its distance to the tectonotal notch. Naturally this is also true for the complete prodorsum being pushed out of and away from the notogaster as already described [23]. During enptychosis it cycles around the tectonotal notch following the course of the deflecting prodorsum before finally being pulled back into the tectonotal notch, where it rests in the encapsulated state. At the same time, the rostral notch of the prodorsum is anchored by the teeth of the lateral anterior tectum (tooth; Fig. 1f), and the prodorsum seals up the encapsulated animal (Fig. 1a, b, f). Overall, the dynamic of enptychosis depicted here matches the former description [23].

Body volume is a critical factor in this behavior, but defense must coexist with other volume-related factors, such as development and laying of eggs, food intake, and defecation. The volume of the eggs inside the morphologically studied mite equates to nearly $13 \%$ of the body volume (Additional file 2: Figure S1). Without a mechanism to compensate, laying all the eggs at once would theoretically render the animal defenseless, but even laying just one egg could severely affect ptychosis. Fecal pellets have not been found in $E$. reticulatus, but one fecal pellet occupies $0.7 \%$ of the total body volume of Phthiracarus longulus Koch [14, 57]. They also found that the

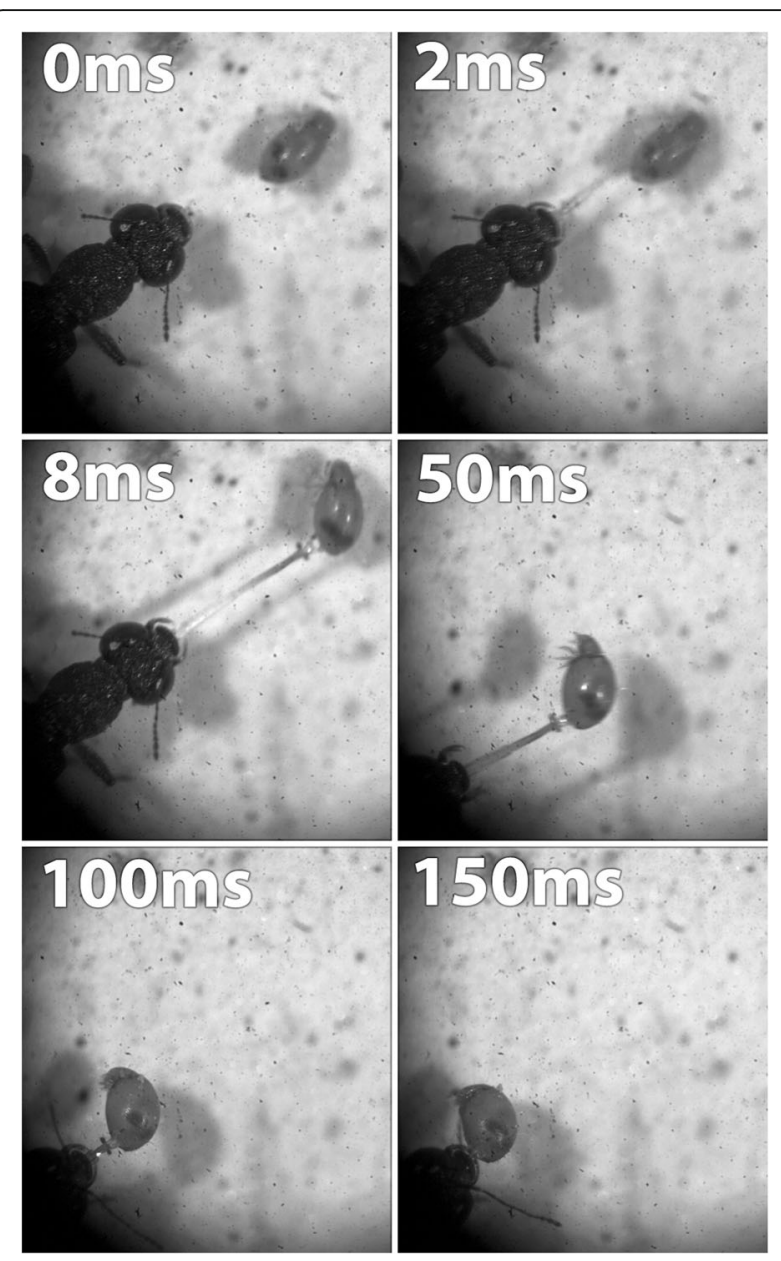

Fig. 10 Time series showing the staphylinid beetle Stenus juno attacking Euphthiracarus reticulatus (see also Additional file 9: Video S2). E. reticulatus shows the first onset of ptychoidy about $50 \mathrm{~ms}$ after the attack and is nearly encapsulated when reaching the predator's mouthparts at the end of the time series (150 ms)

theoretical body volume changes by $2-4 \%$ during ptychosis in species of Phthiracaridae and Euphthiracaridae. A controlled uptake and release of materials such as water, food, feces, and eggs seem to be the most likely scenario for remaining defensible.

The analysis of cross section area showed a difference of about $10 \%$ between extended and encapsulated states. This is large in comparison to the volume change of P. longulus and Acrotritia ardua Koch [14], but the area value does not include the converse change in notogaster length (about 1.4\%) acting as a 'volumetric buffer' (i.e., if the cross-section area increases, notogaster length decreases and vice versa). However, the degrees of notogastral compression we observed in vivo are probably not the possible extremes. There could be more latitude for compression and decompression of the notogaster and thus compensation for feeding, oviposition, and defecation. 
The latitude of important muscles also may be greater than the observed extremes. For example, we found the nlc length to change by about $20 \%$ during ptychosis, higher than insect muscles that often shorten by just $5 \%$ in vivo [59]. Striated muscles in general seem to have even more latitude as observed values for contraction (35 and 50\%, respectively) and stretching (115\%) of the resting length show $[46,47]$. If we assume that the maximum measured nlc length is the resting length, and if these general figures apply, the latitude may be enough to compensate for uptake and release of materials, even the simultaneous release of multiple eggs.

Phthiracaroid species have a change in volume during ptychosis similar to that of euphthiracarid species [14], but build up pressure by retracting the ventral plates (anal and genital venter are in contrast to Euphthiracaroidea not fused thus not holoventral plates) into the body based on a contraction of the muscles $n l c$ and poam. Both muscles, however, are only capable of retracting the ventral plates into the body as long as the direction of their force vectors allows for it. A contraction of the poam for example can no longer lead to a retraction of the ventral plates into the body when its origin on the notogaster, insertion on the postanal apodeme of the ventral plates, and the fulcrum point of the ventral plates form a straight line. Thus, the muscles associated with the build of pressure in Phthiracaroidea do not have as much latitude and accordingly the number of eggs that can be laid simultaneously should be lower than in euphthiracaroid species.

\section{Chemistry}

\section{A novel natural product: $\delta$-acaridial}

We characterized the molecular structure of the novel compound, 2-(but-1-en-1-yl)-4-butylidene-3(pent-2-en-1-yl)-pentanedial, using EI-MS, HRMS and NMR. CAS database searches showed no similar structures and to the best of our knowledge the structure has not been described as a natural compound from any source. Hence, in the tradition of common names of dialdehydes isolated from other mites [60-62], we suggest the trivial name " $\delta$-acaridial".

While aldehydes and dialdehydes are commonly known structural elements in exocrine chemistry of mites [30, 60-64], the structure and chemical properties of $\delta$-acaridial are unusual. For instance, the performed micro-reactions (MOX and TMCS derivates) indicated two carbonyl groups, of which one was enolisable to its corresponding hydroxyl group in pyridine (Additional file 8: Figure S5). It is uncertain if this keto-enol tautomerism, especially the relocation of the hydrogen from the alpha carbon, also occurs under natural conditions in the oil gland reservoirs in the absence of a Lewis base (e.g., pyridine). Furthermore, in oil gland extracts $\delta$-acaridial readily isomerizes to at least three more isomers (all $\mathrm{m} / z=276$, see Additional file 13, Additional file 8: Figure S5 and [64]), if stored at room temperature before GC/MS analysis. Since rearrangement reactions are known to cause artificial results in oribatid mites [65], we consider the three other isomers as artifacts and only $\delta$-acaridial as a naturally occurring gland exudate.

The biochemical origin of $\delta$-acaridial is ambiguous. Considering the biosynthetic pathways described for mites [66-71] and compounds detected in species closely related to $E$. reticulatus two seem possible: the terpenoid synthesis via the mevalonic acid pathway, or the fatty acid synthesis pathway (and derived compounds). Terpenoid synthesis is unlikely, since $\delta$-acaridial lacks any isoprenoid subunit, which is the defining structural element for all terpenes, but $\delta$-acaridial may be a highly modified derivative or a product by an extremely altered terpenoid biosynthesis pathway. However, also a natural derivate arising from fatty acid synthesis seems possible, because in mites some fatty acid derivatives appear to constitute some rather usual substances [71]. Yet, mites are prone to use extraordinary ways to produce their chemicals and thus novel biochemical reactions or unexpected modifications from a known pathway would be not surprising $[67,70,71]$.

\section{A chemo-evolutionary scenario for Ptyctima}

Although chemical data on oil gland secretions in the middle-derivative oribatid mite infraorder Mixonomata are relatively limited, our results and comparative literature data allow the proposal of a preliminary chemo-evolutionary scenario for the speciose subgroup Ptyctima. The phylogenetic underpinning is not certain, but Euphthiracaridae appear to be a derived family within Euphthiracaroidea, based on morphological data [72, 73]; it forms a clade with Oribotritiidae, although the latter family may be paraphyletic with respect to the former. The third euphthiracaroid family, Synichotritiidae, is thought to be their outgroup. The monofamilial Phthiracaroidea is usually considered the sister-group of Euphthiracaroidea, with the two comprising the Ptyctima. Since the suspected outgroups of Ptyctima - Collohmannioidea, Epilohmannioidea [74] - are glandulate, it seems certain that the ancestor of Ptyctima was also glandulate. In this concept, the glands have been lost from Phthiracaroidea and Synichotritiidae but retained by Euphthiracaridae and Oribotritiidae. Surprisingly few Ptyctima have been included in molecular studies, but that of Pachl et al. [35] contradicts morphology by suggesting that Phthiracaroidea were derived within Oribotritiidae. As yet, Synichotritiidae have not been part of molecular studies.

The major groups of glandulate oribatid mites are generally characterized by a certain group of oil gland compounds. One taxonomically important set of chemicals 
are the so called "astigmatid compounds" [75], which evolved within the basal mixonomatans. Astigmatid compounds consist mainly of different terpenes (neral, geranial, neryl formate) and aromatics (2-hydroxy-6-methyl-benzaldehyde, $\gamma$-acaridial). This set of compounds [76] is found in Collohmannioidea, a proposed sister-group [74, 77] of Ptyctima (Fig. 11). Within Ptyctima the euphthiracaroid family Oribotritiidae retain certain hydrocarbons and terpenes (i.e., 6,9-heptadecadiene, 8-heptadecene, neral and geranial) $[36,78,79]$, consistent with their less-specialized morphology and suspected basal position, but both substance classes are absent from known Euphthiracaridae.

If Oribotritiidae and Euphthiracaridae are sister-families, as depicted in Fig. 11, then the detected diterpenoid $\beta$-springene $[36,78,79]$ can be considered a synapomorphy that may have evolved in the basal Oribotritiidae together with other iridoid monoterpenes (see below) that incrementally replaced the astigmatid compound terpenes. At the same time, each family appears to be distinguishable by a compound not shared with the other. By contrast, chrysomelidials-the diastereomers chrysomelidial $(=3 S, 8 S$-chrysomelidial $)$ and epi-chrysomelidial $(=3 S, 8 R$-chrysomelidial)-appear to be widely distributed among Euphthiracaroidea [63, 64, 78, 79]. In the genus Euphthiracarus, however, chrysomelidials appear to have been lost, while the newly described compound $\delta$-acaridial, was added to at least part of the genus $[63,64]$. Such regressive evolutionary trends (i.e. replacement/reduction of new evolved compounds or gland reduction) seem to be common in oribatid mites [80] not only with respect to component diversity but also to volume. For example, Collohmanniidae have notably larger secretion volume (approx. $7 \mu \mathrm{g}$; [81]) than Oribotritiidae (approx. $3 \mu \mathrm{g}$; [79]), which in turn are larger than in Euphthiracaridae (approx. $100 \mathrm{ng}$; this study). The complete absence of glands in Phthiracaridae [63] and Synichotritiidae appear to represent the culmination of such a trend.

\section{Predation experiments}

Due to their defense mechanisms, oribatid mite adults are thought to live in a conceptual 'enemy-free space' [9, $10,32]$, since only a few examples of specialized or generalist predators have been demonstrated. Depending on the size and feeding type of the predator, different mechanisms of defense (chemical, morphological, behavioral) seem most important [7-9, 32]. For the oribatid mite Archegozetes longisetosus Aoki, chemical defense was effective against a large predator (the rove beetle Stenus juno; $[9,12,32])$, but the degree of sclerotization became much more important when predators were small (the gamasid mite Stratiolaelaps miles; [8]). Euphthiracarus reticulatus, on the other hand, was perfectly protected

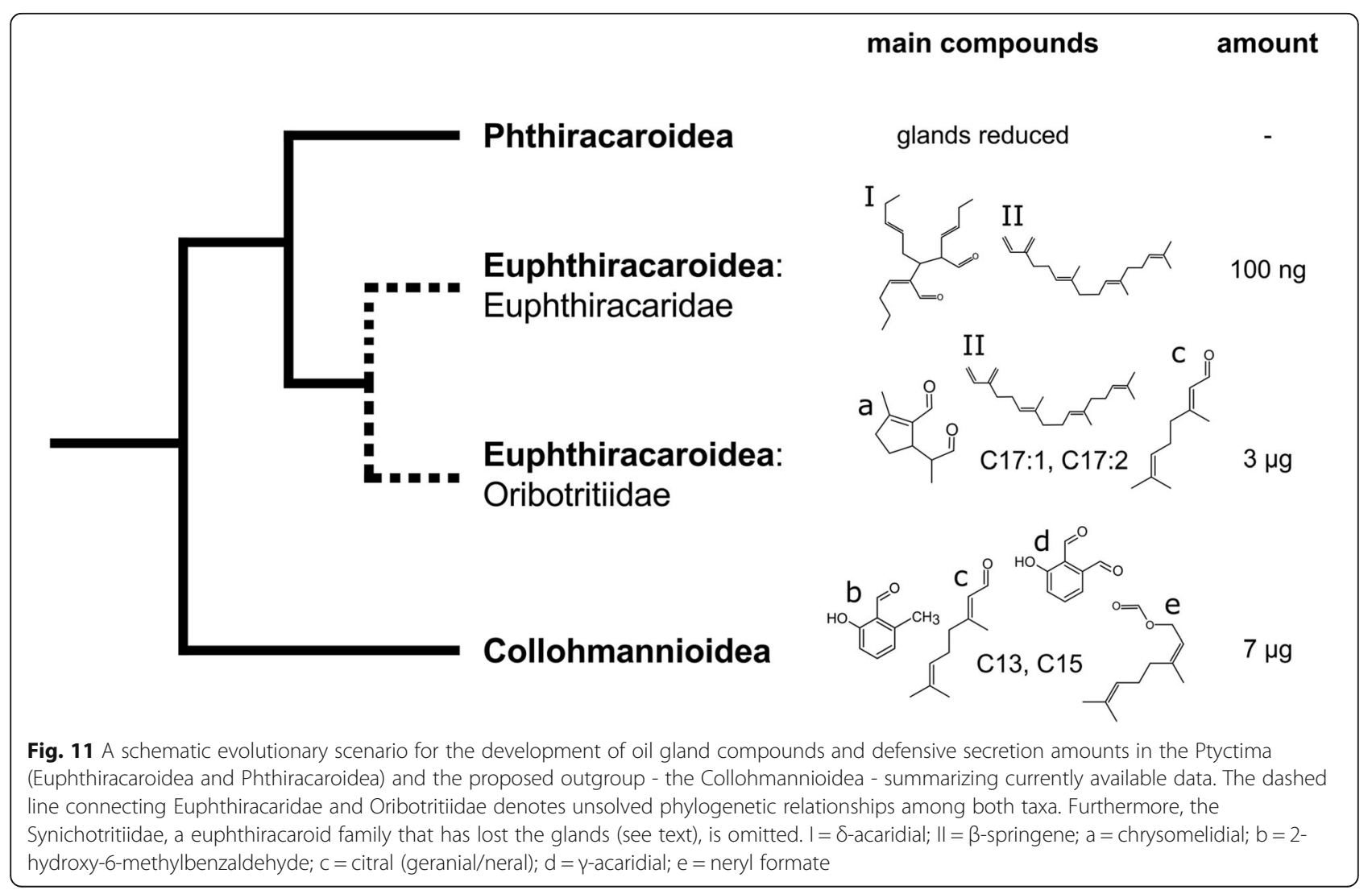


against both of these predators, with or without oil-gland secretions. When the mites were chemically defended, the handling time of S. juno, however, was significantly reduced (Fig. 9), indicating a repellent effect of oil-gland secretions. By contrast, only chemically defended specimens were able to repel O. punctulatus, an even larger rove beetle with a strong cracking mandible type (Additional file 10: Video S3). As in all Euphthiracaroidea, the notogaster of $E$. reticulatus is characterized by lateral elasticity to enable volume/pressure-control during ptychoidy (Additional file 1: Video S1), and this lack of total rigidity may allow such attacks.

The Phthiracaroidea encapsulate by a different mechanism, without lateral compression, and the encapsulated body has no elastic elements [14, 56, 57]. Despite the absence of oil-glands in these mites, O. punctulatus was not able to feed on Phthiracarus sp. (Additional file 10: Video S3). Phthiracaroidea are well-known for their rigid bodies, with various degrees of cuticular deposition of calcium carbonate as a hardening agent [21]. Although Phthiracarus species are at the lower end of the spectrum it still seems effective. The euphthiracaroid family Synichotritiidae similarly have strong mineralization and lack oil-glands. Some even have a ptychoid mechanism convergently similar to that of Phthiracaroidea, though it is poorly known [73].

Taken together, these data and observations suggest that the reduction or loss of glands can be interpreted as an evolutionary trend toward putting reliance on the combination of ptychoidy and cuticular hardness as an effective defense mechanism. Old observations, however, showed that powerful generalized predators like the beetle family Ptiliidae can overcome phthiracarid defenses [82], and specialized predators like the scydmaenid beetle Euconnus pubicollis Müller \& Kunze even generally prefers phthiracaroid over euphthiracaroid mites, though chemical defense seem not responsible for this [39].

\section{Conclusion}

Oribatid mites exhibit a huge diversity of morphological, behavioral, and chemical anti-predator adaptations to oppose a similarly huge diversity of small and large predators with different feeding types and mouthpart morphologies. The complexity and interplay of defensive adaptations cannot be understood in isolation - hence we investigated the "holistic" defense of morphology and chemistry in light of structure and function. We have shown that anti-predator adaptations can be understood only in the context of who the predator is and how it feeds. Organisms that face the diversity of soil predators will probably survive on evolutionary time-scales only with a combination of several strategies. For a sound understanding of trophic interactions in soil it therefore seems mandatory to include such factors in food-web-models, rather than relying on body-mass-relationships alone.

\section{Additional files}

Additional file 1: Video S1. Enptychosis (the process of encapsulation) and ecptychosis (the process of extension) of the ptychoid box mite Euphthiracarus reticulatus. (MP4 23249 kb)

Additional file 2: Figure S1. Transparent 3D model of Euphthiracarus reticulatus (single material model in green) overlaying two 'immature' and six 'mature' eggs from the morphological 3D model. (A) Perspective, anteroventral view. (B) Orthographic, lateral view. (C) Orthographic, ventral view. (TIF 5699 kb)

Additional file 3: Additional information for sections Morphology and Chemistry as well as Tables S1 - S4. (PDF 239 kb)

Additional file 4: Figure S2. Landmarks (A - C) and calculated distances (D - E) based on said landmarks (cf. Additional file 3: Table S1 and S2). A, D) Lateral view of live radiography data. B, E) Ventral view of live radiography data. C, F) Frontal view of live radiography data. Insets show a more detailed view of respective regions. (TIF $13549 \mathrm{~kb}$ )

Additional file 5: Figure S3. Voxel rendering showing the position of the gladius of the preanal apodeme ( $\mathrm{gl}$ pra). (TIF $1498 \mathrm{~kb}$ )

Additional file 6: Figure S7. 3D-models of reconstructed Synchrotron X-ray micro tomography data of exoskeletal and muscular elements. A, B) Prodorsum (yellow) with sensillus and bothridial labyrinth underneath. Note the inconspicuous inferior retractor process (irp). C) Coxisternal retractor (csr) and associated exoskeletal elements (with transparent notogaster). D) Inferior prodorsal retractor (ipr) and associated exoskeletal elements (with transparent notogaster). Both, bothridial labyrinth; bs, bothridial scale; car, carinae of the prodorsum; csr, coxisternal retractor; $\mathrm{HV}$, holoventral plates; ipr, inferior prodorsal retractor; irp, inferior retractor process; legs, walking legs I - IV; mn, manubrium; NG, notogaster; PL, plicature plates; PR, prodorsum; sa, sagittal apodeme; ss, sensillus. (TIF 3634 kb)

Additional file 7: Figure S4. Multiplicity edited ${ }^{1} \mathrm{H}-{ }^{13} \mathrm{C}$ correlations of $\delta$-acaridial. Positive signals (blue) indicate either $\mathrm{CH}$ or $\mathrm{CH}_{3}$ groups, whereas negative signals (red) are indicative of $\mathrm{CH}_{2}$. (A) ${ }^{1} \mathrm{H}^{-13} \mathrm{C} \mathrm{HSQC}$ spectrum optimized for the aliphatic region $\left({ }^{13} \mathrm{C}\right.$ offset: $\left.70 \mathrm{ppm}\right)$ recorded at $700 \mathrm{MHz}$ and $274 \mathrm{~K}$ using 240 transients, $4 \mathrm{k} \times 150$ data points with spectral widths of $10 \times$ 145 ppm, corresponding to a digital resolution of $3.5 \mathrm{~Hz}$ in $\mathrm{f} 2$ and $1.9 \mathrm{ppm}$ in f1, resulting in a measurement time of $23 \mathrm{~h}$. Positive signals (red) indicate either $\mathrm{CH}$ or $\mathrm{CH}_{3}$ groups, whereas negative signals (blue) are indicative of $\mathrm{CH}_{2}$. A contamination with hexane is indicated with grey labels. (B) ${ }^{1} \mathrm{H}^{-13} \mathrm{C}$ HSQC optimized for the aldehyde and olefin groups ( ${ }^{13} \mathrm{C}$ offset: $150 \mathrm{ppm}$, INEPT delay was optimized for $\mathrm{J}_{\mathrm{CH}}=172 \mathrm{~Hz}$ ) recorded at $700 \mathrm{MHz}$ and $274 \mathrm{~K}$ using 240 transients, $4 \mathrm{k} \times 274$ data points with spectral widths of $10 \times$

$200 \mathrm{ppm}$, corresponding to a digital resolution of $3.5 \mathrm{~Hz}$ in $\mathrm{f} 2$ and $1.5 \mathrm{ppm}$ in $\mathrm{f1}$, resulting in a measurement time of $35 \mathrm{~h}$. For nomenclature see Fig. 8. (TIF $828 \mathrm{~kb}$ )

Additional file 8: Figure S5. Keto-enol tautomerism of $\delta$-acaridial. C2 (a-carbon) is located next to the aldehyde group and thus possess an acidic proton, prone to keto-enol tautomerism. Note that this reaction only appears to occur in Lewis bases like pyridine. (TIF 887 kb)

Additional file 9: Video S2. Highspeed recording (at 500 frames per second) showing the predatory staphylinid beetle Stenus juno attacking a specimen of Euphthiracarus reticulatus. (MP4 $11142 \mathrm{~kb}$ )

Additional file 10: Video S3. The predatory staphylinid beetle Othius punctulatus successfully attacking a specimen of Euphthiracarus reticulatus but failing to feed on a specimen of Phthiracarus. (MP4 68352 kb)

Additional file 11: Video S5. Defecation in Euphthiracarus reticulatus. Note the laterally flattened fecal pellet. (MP4 $14326 \mathrm{~kb}$ )

Additional file 12: Video S4. Cineradiography data showing enptychosis of adult Euphthiracarus reticulatus from different viewing angles. Upper left side, lateral view; lower left side, ventral view; right side, frontal view. (MP4 13205 kb)

Additional file 13: Figure S6. Gas chromatographic traces and mass spectrometric data of the defensive secretion compounds of Euphthiracarus reticulatus if the samples were shortly $(<1 \mathrm{~h})$ stored at room temperature before GC/MS analysis. (TIF 894 kb)

Additional file 14: Interactive 3D content of Fig. 2. (PDF $2100 \mathrm{~kb}$ ) 


\section{Abbreviations}

${ }^{\circ} \mathrm{C}$ : Temperature in degrees Celsius; 2D: Two dimensional; 3D: Three dimensional; aa: Anal atrium; br: Broad; cm: Centimeter; csr: Coxisternal retractor; D: Deuterium; d: Doublet; df: Degrees of freedom; ESI-

MS: Electrospray ionization - mass spectrometry; EtOH: Ethanol; eV: Electron volt; FAE: 3:6:1; VNN mixture of 35\% formaldehyde, $80 \%$ ethanol, and 100\% acetic acid; FID: Flame ionization detector; g: Gram; GC: Gas chromatograph;

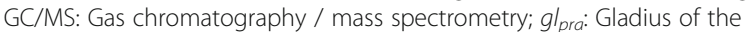
preanal apodeme; h: Hour; HMBC: Heteronuclear multiple-bond correlation; HPLC: High performance liquid chromatography; HPLC-MS: High performance liquid chromatography - mass spectrometry; HRMS: Highresolution mass spectrometry; HSQC: Heteronuclear single quantum correlation; Hz: Hertz (frequency); ID: Identification; ipr: Inferior prodorsal retractor; IUPAC: International Union of Pure and Applied Chemistry; keV: Kiloelectronvolt; kV: Kilovolt; Irm: Lateral rectal muscle; m: Depending on context: meter, multiplet, mass (see $\mathrm{m} / \mathrm{z}$ ); M: Molar concentration in $\mathrm{g} / \mathrm{mol}$; m/z: Mass/charge ratio; $\mathbf{M}^{+}$: Molecular ion; $\mathrm{mg}$ : Milligram; $\mathbf{M H z}$ : Megahertz; min: Minute; MI: Milliliter; mm: Millimeter; MMl: Multimode inlet; mol: Mole; MOX: Methoxyamine-hydrogen chloride; ms: Milliseconds; MSTFA: N-methyl$\mathrm{N}$-(trimethylsilyl)-trifluoracetamid; N: Sample size; n.d.: Not detectable; nlc: Notogaster lateral compressor muscle; nm: Nanometer; NMR: Nuclear magnetic resonance spectroscopy; ovlp: Overlapped signals; pcGC: Preparative capillary gas chromatography; PFC: Preparative fraction collector; poam: Postanal muscle; ppm: Parts per million; PTV: Programmed temperature vaporization; RI: Retention index; sec: Second; SRHCT: Synchrotron X-ray microtomography; t: Triplet; TMCS: Trimethylchlorosilane; TMS: Tetramethylsilane; TOCSY: Total correlation spectroscopy; VN: Volume to volume mixing ratio; vpa: Ventral plate adductor; $v p c$ : Ventral plate compressor; $\mu$ l: Microliter; $\mu \mathrm{m}$ : Micrometer

\section{Acknowledgements}

We thank Thomas van de Kamp, Tomy dos Santos Rolo, and Tomáš Faragó for their help during data acquisition and reconstruction of tomographic data; Norbert Müller and Maria Theresia Pöschko for help in setting up NMR measurements; Herbert Kogler for verifying the structure determination by going through the NMR spectra at the Austrian NMR Summer School; HansJörg Leis and Irmgard Schäffler for their help with HRMS and pcGC, respectively; Wojciech Niedbała for his help in the determination of the species; and Alexander Schneider for his assistance with the Othius punctulatus video recordings.

\section{Funding}

Adrian Brückner was supported by a scholarship for undergraduate students, a PhD grant, and two short-term research stipends provided by the German National Academic Foundation (Studienstiftung des deutschen Volkes). Günther Raspotnig received financial support from Pro Acarologia Basiliensis (PAB). The synchrotron data was obtained within the BMBF-projects ASTOR and NOVA (05K13VTA, 05K16RDD). Michael Heethoff was supported by the German Research Foundation (HE4593/3-1 and HE4593/5-1). The $700 \mathrm{MHz} N M R$ experiments were performed at the Upper Austrian - South Bohemian Research Infrastructure Center "RERI-uasb" at Johannes Kepler University in Linz, co-financed by the European Union in the context of the project EFRE RU2-EU124/100-2010 (ETC Austria-Czech Republic 2007-2013, project M00146). We acknowledge support by the German Research Foundation and the Open Access Publishing Fund of Technische Universität Darmstadt

\section{Availability of data and materials}

Morphological data are deposited in MorphDBase repository under accession number: S_Schmelzle_20180122-M-67-001.1 (link: http://www.morphdbase.de/ ?S_Schmelzle_20180122-M-67.1). The raw chemical data analyzed for the current study are available from the corresponding author upon request. All other materials are attached as supplementary files.

\section{Authors' contributions}

Idea and design of the study: $M H, G R, A B, S S, R A N$; Animal sampling: $A B, M H$, GR; Collection and analyses of chemical data: $A B, G R, M H, S D$; Collection and analyses of NMR data: MS, RM, MB; Collection and analysis of morphological data: SS, MH; Predator-prey bioassays: MH, SS; Manuscript drafting: MH, AB, SS, RAN. Equal contributions: MH, AB, SS, MS. All authors read and approved the final manuscript.

\section{Ethics approval}

Not applicable.

\section{Consent for publication}

Not applicable.

Competing interests

The authors declare that they have no competing interests.

\section{Publisher's Note}

Springer Nature remains neutral with regard to jurisdictional claims in published maps and institutional affiliations.

\section{Author details}

${ }^{1}$ Ecological Networks, Technische Universität Darmstadt, Schnittspahnstraße 3, 64287 Darmstadt, Germany. ${ }^{2}$ Institute of Biology, University of Graz, Universitätsplatz 2, 8010 Graz, Austria. ${ }^{3}$ Department of Biosciences, University of Salzburg, Billrothstrasse 11, 5020 Salzburg, Austria. ${ }^{4}$ Institute of Organic Chemistry, Johannes Kepler University Linz, Altenbergerstraße 69, 4040 Linz, Austria. ${ }^{5} \mathrm{Clemens}$-Schöpf-Institute of Organic Chemistry and Biochemistry, Technische Universität Darmstadt, Alarich-Weiss-Str. 4, 64287 Darmstadt, Germany. ${ }^{6}$ Department of Biosciences, University of Salzburg, Hellbrunnerstraße 34, 5020 Salzburg, Austria. ${ }^{7}$ State University of New York, College of Environmental Science and Forestry, 1 Forestry Drive, Syracuse, NY 13210, USA. ${ }^{8}$ Present address: Division of Biology and Biological Engineering, California Institute of Technology, 1200 E. California Boulevard, Pasadena, California 91125, USA.

Received: 23 February 2018 Accepted: 15 June 2018

Published online: 13 August 2018

\section{References}

1. Anderson JM. The enigma of soil animal diversity. In: Vanek J, editor. Proceedings of the 5th international colloquium on soil zoology held in Prague September 17-22 1973. Prague: Academia; 1975. p. 51-8.

2. Giller PS. The diversity of soil communities, the 'poor man's tropical rainforest. Biodivers Conserv. 1996;5:135-68.

3. Macfadyen A. Improved funnel-type extractors for soil arthropods. J Anim Ecol. 1961;30:171-84.

4. Brose $U$, Scheu $\mathrm{S}$. Into darkness: unravelling the structure of soil food webs. Oikos. 2014;123:1153-6.

5. Brose U. Body-mass constraints on foraging behaviour determine population and food-web dynamics. Funct Ecol. 2010;24:28-34.

6. Scheu S, Falca M. The soil food web of two beech forests (Fagus sylvatica) of contrasting humus type: stable isotope analysis of a macro-and a mesofauna-dominated community. Oecologia. 2000;123:285-96.

7. Boukal DS. Trait- and size-based descriptions of trophic links in freshwater food webs: current status and perspectives. J Limnol. 2014;73:171-85.

8. Brückner A, Wehner K, Neis M, Heethoff M. Attack and defense in a gamasid-oribatid mite predator-prey experiment - sclerotization outperforms chemical repellency. Acarologia. 2016;56:451-61.

9. Heethoff M, Koerner L, Norton RA, Raspotnig G. Tasty but protected-first evidence of chemical defense in oribatid mites. J Chem Ecol. 2011;37:1037-43.

10. Peschel K, Norton RA, Scheu S, Maraun M. Do oribatid mites live in enemyfree space? Evidence from feeding experiments with the predatory mite Pergamasus septentrionalis. Soil Biol Biochem. 2006;38:2985-9.

11. Pomini AM, Machado G, Pinto-da-Rocha R, Macias-Ordonez R, Marsaioli AJ. Lines of defense in the harvestman Hoplobunus mexicanus (Arachnida: Opiliones): aposematism, stridulation, thanatosis, and irritant chemicals. Biocheml Syst Ecolo. 2010;38:300-8.

12. Heethoff $M$, Rall BC. Reducible defence: chemical protection alters the dynamics of predator-prey interactions. Chemoecology. 2015;25:53-61.

13. Norton RA. Holistic acarology and ultimate causes: examples from the oribatid mites. In: Malacara JB, Behan-Pelletier V, Ueckermann E, Perez TM, Estrada-Venegas EG, Badii M, editors. Acarology XI: proceedings of the international congress. Mexico City: Sociedad Latinoamericana de Acarologia; 2007. p. 3-20.

14. Schmelzle S, Norton RA, Heethoff M. Mechanics of the ptychoid defense mechanism in Ptyctima (Acari, Oribatida): one problem, two solutions. Zoolo Anz - J Comp Zool. 2015;254:27-40. 
15. Heethoff M, Norton RA, Scheu S, Maraun M. Parthenogenesis in oribatid mites (Acari, Oribatida): evolution without sex. In: Schön I, Martens K, van Dijk P, editors. Lost sex: the evolutionary biology of parthenogenesis. Dordrecht: Springer; 2009. p. 241-57.

16. Schatz H. Diversity and global distribution of oribatid mites (Acari, Oribatida): evaluation of the present state of knowledge. Phytophaga. 2004; 14:485-500.

17. Subias LS. Listado sistemático, sinonímico y biogeográfico de los ácaros oribátidos (Acariformes, Oribatida) del mundo. Graellisa. 2004;60:3-305.

18. Wehner K, Norton RA, Blüthgen N, Heethoff M. Specialization of oribatid mites to forest microhabitats—the enigmatic role of litter. Ecosphere. 2016; 7:ecs2.1336.

19. Schneider K, Maraun M. Top-down control of soil microarthropods evidence from a laboratory experiment. Soil Biol Biochem. 2009:41:170-5.

20. Alberti G, Norton RA, Kasbohm J. Fine structure and mineralisation of cuticle in Enarthronota and Lohmannioidea. In: Haliday RB, Walter DE, Proctor HC, Norton RA, Colloff MJ, editors. Acarology: proceedings of the 10th international congress. Melbourne: CSIRO Publishing; 2001. p. 230-41.

21. Norton RA, Behan-Pelletier VM. Calcium carbonate and calcium oxalate as cuticular hardening agents in oribatid mites (Acari: Oribatida). Cana J Zool. 1991:69:1504-11.

22. Norton RA, Behan-Pelletier VM. Epicuticular calcification in Phyllozetes. Modern Acarology. 1991;2:323-4.

23. Sanders FH, Norton RA. Anatomy and function of the ptychoid defensive mechanism in the mite Euphthiradarus cooki (Acari: Oribatida). J Morphol. 2004:259:119-54

24. Krisper G. Das Sprungvermögen der Milbengattung Zetorchestes (Acari, Oribatida). Zoolo Jahr Abt Anat Onto Tiere. 1990;120:289-312.

25. Wauthy G, Leponce M, Bana N, Sylin G, Lions JC. The backward jump of a box moss mite. Proc Roy Soc B: Biolo Sci. 1998:265:2235-42.

26. Brückner A, Raspotnig G, Wehner $K$, Meusinger R, Norton RA, Heethoff M. Storage and release of hydrogen cyanide in a chelicerate (Oribatula tibialis). Proc Natl Acad Sci U S A. 2017;114:3469-72.

27. Heethoff M, Norton RA, Raspotnig G. Once again: oribatid mites and skin alkaloids in poison frogs. J Chem Ecol. 2016;42:841-4.

28. Raspotnig G. Chemical alarm and defence in the oribatid mite Collohmannia gigantea (Acari: Oribatida). Exp Appl Acarol. 2006;39:177-94.

29. Raspotnig G. Characterisation of monophyletic oribatid groups by oil gland chemistry - a novel systematic approach in Oribatida (Acari). Abh Ber Naturkundemus Görlitz. 2006;78:31-46.

30. Raspotnig G, Norton RA, Heethoff M. Oribatid mites and skin alkaloids in poison frogs. Biol Lett. 2011;7:555-6.

31. Saporito RA, Donnelly MA, Norton RA, Garraffo HM, Spande TF, Daly JW. Oribatid mites as a major dietary source for alkaloids in poison frogs. Proc Natl Acad Sci U S A. 2007:104:8885-90.

32. Heethoff M, Raspotnig G. Expanding the 'enemy-free space' for oribatid mites: evidence for chemical defense of juvenile Archegozetes longisetosus against the rove beetle Stenus juno. Exp Appl Acarol. 2012; 56:93-7.

33. Hansen RA. Effects of habitat complexity and composition on a diverse litter microarthropod assemblage. Ecology. 2000;81:1120-32.

34. Schmelzle S, Helfen L, Norton RA, Heethoff M. The ptychoid defensive mechanism in Euphthiracaroidea (Acari: Oribatida): a comparison of muscular elements with functional considerations. Arthropod Struct Dev. 2009:38:461-72

35. Pachl P, Domes K, Schulz G, Norton RA, Scheu S, Schaefer I, Maraun M. Convergent evolution of defense mechanisms in oribatid mites (Acari, Oribatida) shows no "ghosts of predation past". Mol Phylogenet Evol. 2012; 65:412-20.

36. Raspotnig G, Kaiser R, Stabentheiner E, Leis HJ. Chrysomelidial in the opisthonotal glands of the oribatid mite, oribotritia berlesei. J Chem Ecol. 2008:34:1081-8.

37. Jaloszynski P, Olszanowski Z. Feeding of Scydmaenus rufus (Coleoptera: Staphylinidae: Scydmaeninae) on oribatid and uropodine mites: prey preferences and hunting behaviour. Eur J Entomol. 2015;112:151-64

38. Jaloszynski P, Olszanowski Z. Feeding of two species of Scydmaeninae "hole scrapers", Cephennium majus and C. ruthenum (Coleoptera: Staphylinidae), on oribatid mites. Eur J Entomol. 2016;113:372-86.

39. Jałoszyński P, Olszanowski Z. Specialized feeding of Euconnus pubicollis (Coleoptera: Staphylinidae: Scydmaeninae) on oribatid mites: prey preferences and hunting behaviour. Eur J Entomol. 2013;110:339-53.
40. Schmid R. Morphologische Anpassungen in einem Räuber-Beute-System: Ameisenkäfer (Scydmaenidae, Staphylinoidea) und gepanzerte Milben (Acari). Zool Jahr. 1988;115:207-28.

41. Wilson EO. Oribatid mite predation by small ants of the genus Pheidole. Insect Soc. 2005;52:263-5.

42. Heethoff M. Regeneration of complex oil-gland secretions and its importance for chemical defense in an oribatid mite. J Chem Ecol. 2012;38:1116-23.

43. Chen $\mathrm{H}, \mathrm{He} X$, Sheng $C$, Ma Y, Nie H, Xia W, Ying W. Interactions between synchrotron radiation $\mathrm{X}$-ray and biological tissues theoretical and clinical significance. International. Int J Physiol Pathophysiol Pharmacol. 2011;3:243-8.

44. Schindelin J, Arganda-Carreras I, Frise E, Kaynig V, Longair M, Pietzsch T, Preibisch S, Rueden C, Saalfeld S, Schmid B, et al. Fiji: an open-source platform for biological-image analysis. Nat Methods. 2012;9:676-82.

45. Schneider CA, Rasband WS, Eliceiri KW. NIH image to ImageJ: 25 years of image analysis. Nat Methods. 2012;9:671-5.

46. Huxley HE, Hanson J. Changes in the cross-striations of muscle during contraction and stretch and their structural interpretation. Nature. 1954;173:973-6.

47. Hanson J, Huxley HE. The structural basis of contraction in striated muscle In: Brown R, Danielli JF, editors. Symposia of the society for experimental biology number 9: fibrous proteins and their biological significance. New York: Academic Press; 1955. p. 228-64.

48. Hoyle G. Neural control of skeletal muscle. In: Rockstein M, editor. The physiology of Insecta. New York and London: Academic Press; 1965. p. 408-50.

49. Van den Dool H, Kratz PD. A generalization of retention index system including linear temperature programmed gas-liquid partition chromatography. J Chromatogr. 1963;11:463-8.

50. Meinert C, Brack W. Optimisation of trapping parameters in preparative capillary gas chromatography for the application in effect-directed analysis. Chemosphere. 2010;78:416-22.

51. Meinert C, Moeder M, Brack W. Fractionation of technical p-nonylphenol with preparative capillary gas chromatography. Chemosphere. 2007;70:215-23.

52. Goddard TD, Kneller DG. SPARKY 3, University of California, San Francisco.

53. Heethoff $M$, Raspotnig $G$. Triggering chemical defense in an oribatid mite using artificial stimuli. Exp Appl Acarol. 2012;56:287-95.

54. Benjamini $Y$, Hochberg Y. Controlling the false discovery rate - a practical and powerful approach to multiple testing. J Roy Stat Soc B. 1995;57:289-300.

55. Schmelzle S, Helfen L, Norton RA, Heethoff M. The ptychoid defensive mechanism in Euphthiracaroidea (Acari: Oribatida): a comparison of exoskeletal elements. Soil Org. 2008;80:233-47.

56. Schmelzle $\mathrm{S}$, Helfen L, Norton RA, Heethoff M. The ptychoid defensive mechanism in Phthiracarus longulus (Acari, Oribatida, Phthiracaroidea): exoskeletal and muscular elements. Soil Org. 2010;82:253-73.

57. Schmelzle S, Norton RA, Heethoff M. A morphological comparison of two closely related ptychoid oribatid mite species: Phthiracarus longulus and $P$. globosus (Acari: Oribatida: Phthiracaroidea). Soil Org. 2012;84:431-43.

58. Heethoff $M$, Norton RA. A new use for synchrotron X-ray microtomography: three-dimensional biomechanical modeling of chelicerate mouthparts and calculation of theoretical bite forces. Invert Biol. 2009;128:332-9.

59. Weis-Fogh T. Tetanic force and shortening in locust flight muscle. J Chem Biol. 1956:33:668-84.

60. Leal WS, Kuwahara Y, Nakano Y, Nakao H, Suzuki T. 2(E)-(4-Methyl-3pentenyl)-butenedial, a-acaridial, a novel monoterpene from the acarid mite Tyrophagus perniciosus (Acarina, acaridae). Agri Biol Chem. 1989;53:1193-6.

61. Leal WS, Kuwahara Y, Suzuki T, Kurosa K. $\beta$-Acaridial, the sex pheromone of the acarid mite Caloglyphus polyphyllae. Naturwissenschaften. 1989;76:332-3.

62. Sakata T, Kuwahara Y. Structural elucidation and synthesis of 3hydroxybenzene-1,2-dicarbaldehyde from astigmatid mites. Biosci Biotechnol Biochem. 2001;65:2315-7.

63. Raspotnig G. Oil gland secretions in Oribatida (Acari). In: Sabelis MW, Bruin J, editors. Trends in acarology. Dordrecht: Springer; 2010. p. 235-9.

64. Sakata T. Natural chemistry of mite secretions: Kyoto University, Kyoto: Faculty of Agriculture; 1997.

65. Heethoff M, Raspotnig G. Is 7-hydroxyphthalide a natural compound of oil gland secretions? - evidence from Archegozetes longisetosus (Acari, Oribatida). Acarologia. 2011:51:229-36.

66. Aboshi T, Shimizu N, Nakajima Y, Honda Y, Kuwahara Y, Amano H, Mori N Biosynthesis of linoleic acid in Tyrophagus mites (Acarina: Acaridae). Insect Biochem Mol Biol. 2013;43:991-6. 
67. Morgan ED. Biosynthesis in insects. Camebridge: RSC Publishing; 2010.

68. Noge K, Kato M, Iguchi T, Mori N, Nishida R, Kuwahara Y. Biosynthesis of neral in Carpoglyphus lactis (Acari: Carpoglyphidae) and detection of its key enzyme, geraniol dehydrogenase, by electrophoresis. J Acarol Soc Jap. 2005; $14: 75-81$

69. Shimizu N, Naito M, Mori N, Kuwahara Y. De novo biosynthesis of linoleic acid and its conversion to the hydrocarbon $(Z, Z)-6,9-$ heptadecadiene in the astigmatid mite, Carpoglyphus lactis: incorporation experiments with ${ }^{13} \mathrm{C}$-labeled glucose. Insect Biochem Mol Biol. 2014:45:51-7.

70. Shimizu N, Sakata D, Miyazaki H, Shimura Y, Kuwahara Y. Identification and synthesis of (Z,Z)-8,11-heptadecadienyl formate and (Z)-8-heptadecenyl formate: unsaturated aliphatic formates found in the unidentified astigmatid mite, Sancassania sp. Sasagawa (Acari: acaridae). Molecules. 2016;21:E619.

71. Shimizu N, Sakata D, Schmelz EA, Mori N, Kuwahara Y. Biosynthetic pathway of aliphatic formates via a Baeyer-Villiger oxidation in mechanism present in astigmatid mites. Proc Natl Acad Sci U S A. 2017:114:2616-21.

72. Haumann G. Zur Phylogenie primitiver Oribatiden (Acari: Oribatida). Graz: Technische Universität Graz; 1991.

73. Norton RA, Lions JC. North American Synichotritiidae (Acari: Oribatida). 1 Apotritia walkeri n.g., n. sp., from California. Acarologia. 1992;33:285-301.

74. Norton RA, Sidorchuk EA. Collohmannia johnstoni n. sp. (Acari, Oribatida) from West Virginia (USA), including description of ontogeny, setal variation, notes on biology and systematics of Collohmanniidae. Acarologia. 2014;54:271-334.

75. Sakata T, Norton RA. Opisthonotal gland chemistry of early-derivative oribatid mites (Acari) and its relevance to systematic relationships of Astigmata. Int J Acarol. 2001;27:281-92.

76. Raspotnig G, Schuster R, Krisper G, Fauler G, Leis HJ. Chemistry of the oil gland secretion of Collohmannia gigantea (Acari: Oribatida). Exp Appl Acarol. 2001;25:933-46.

77. Grandjean F. Considerations sur le classement des oribates leur division en 6 groupes majeurs. Acarologia. 1969;11:127-53.

78. Raspotnig G, Leutgeb V, Krisper G, Leis H-J. Discrimination of Oribotritia species by oil gland chemistry (Acari, Oribatida). Exp Appl Acarol. 2011;54: $211-24$

79. Shimizu N, Yakumaru R, Sakata T, Shimano S, Kuwahara Y. The absolute configuration of chrysomelidial: a widely distributed defensive component among oribotririid mites (Acari: Oribatida). J Chem Ecol. 2012;38:29-35.

80. Raspotnig G, Stabentheiner E, Föttinger P, Schaider M, Krisper G, Rechberger G, Leis HJ. Opisthonotal glands in the Camisiidae (Acari, Oribatida): evidence for a regressive evolutionary trend. J Zool Syst Evol Res. 2009;47:77-87.

81. Raspotnig G, Föttinger P. Analysis of individual oil gland secretion profiles in oribatid mites (Acari: Oribatida). Int J Acarol. 2008;34:409-17.

82. Riha G. Zur Ökologie der Oribatiden in Kalksteinböden. Zool Jahr. 1951:80: $407-50$

\section{Ready to submit your research? Choose BMC and benefit from:}

- fast, convenient online submission

- thorough peer review by experienced researchers in your field

- rapid publication on acceptance

- support for research data, including large and complex data types

- gold Open Access which fosters wider collaboration and increased citations - maximum visibility for your research: over $100 \mathrm{M}$ website views per year

At BMC, research is always in progress.

Learn more biomedcentral.com/submissions 